Draft December, 13, 2021

This paper has not been peer reviewed

\author{
Development and Validation of a Goal Characteristics Questionnaire \\ Gabriela Iwama $^{1}$; Felix Weber ${ }^{2}$; Mike Prentice ${ }^{1}$; Falk Lieder ${ }^{1}$ \\ ${ }^{1}$ Max Planck Institute for Intelligent Systems, Tübingen, Germany \\ ${ }^{2}$ Institute of Cognitive Science, Universität Osnabrück, Osnabrück, Germany
}

\begin{abstract}
Author Note
Gabriela Yukari Iwama (D) https://orcid.org/0000-0002-4043-1230

Felix Weber (iD https://orcid.org/0000-0002-7012-3378

Mike Prentice (D) https://orcid.org/0000-0001-7852-075X

Falk Lieder (iD https://orcid.org/0000-0003-2746-6110

Data available at https://osf.io/3gxk5/?view_only=1ff0e62127c64b82862a0fe7d73c4faf

We have no known conflict of interest to disclose.

Correspondence concerning this article should be addressed to Gabriela Iwama, MPI for Intelligent Systems, Max Planck Ring 4, D-72076 Tübingen. E-Mail:

gabriela.yukari.iwama@gmail.com
\end{abstract}




\begin{abstract}
How motivated a person is to pursue a goal may depend on many different properties of the goal, such as how specific it is, how important it is to the person, and how actionable it is. Rigorously measuring all of the relevant goal characteristics is still very difficult. Existing measures are scattered across multiple research fields. Some goal characteristics are not yet covered, while others have been measured under ambiguous terminology. Other conceptually related characteristics have yet to be adapted to goals. Last but not least, the validity of most measures of goal characteristics has yet to be assessed. The aim of this study is to: a) integrate, refine, and extend previous measures into a more comprehensive battery of self-report measures, the Goal Characteristics Questionnaire (GCQ; https://osf.io/ \{masked for review\}), and b) investigate its evidence of validity. In two empirical studies, this paper provides evidence for the validity of the measures regarding their internal structure, measurement invariance, and convergence and divergence with other relevant goal-related measures, such as the motivation, affect, and the dimensions of Personal Project Analysis. The results show that our goal characteristic dimensions have incremental validity for explaining important outcomes, such as goal commitment and well-being. It concludes with practical recommendations for using the GCQ in research on goal-setting and goal-pursuit, and a discussion about directions for future studies.
\end{abstract}

Keywords: goal characteristics, goal setting, goal pursuit, questionnaire, psychometrics 


\section{Development and Validation of a Goal Characteristics Questionnaire}

Goals are one of the fundamental concepts in motivation science. They can be defined as "internal representations of desired states" (Austin \& Vancouver, 1996, p. 338) that can guide behavior at both conscious and unconscious levels (Bargh et al., 2001). Goals can vary on several reasonably obvious dimensions, such as duration in time, difficulty, and abstraction. For example, a short, easy, and concrete goal might be to reply to three emails in the next 15 minutes. A longer-term, challenging, and abstract goal might be to increase insight into one's own behaviors. An essential task of research on goals is to discover and adequately measure the characteristics of the goal that are important for goal-pursuit processes, the goal's outcomes, and people's lives more generally.

Over the years, an enormous amount of research from across many disciplines has investigated goals and attempted to describe their key features, functioning, and effects (e.g., Chidester \& Grigsby, 1984; Kleingeld et al., 2011; Mento et al., 1987; Wood et al., 1987). Initial attempts to measure important characteristics or consequences of psychological phenomena in emerging research areas are often somewhat piecemeal. Ideally, sustained inquiry develops toward elaboration and systematization of measurement approaches. The attempt to characterize aspects of people's goals is paradigmatic of this elaboration process but remains at the elaboration stage and a lot of work remains to be done. This state of affairs leaves the possibility that essential goal characteristics and valuable targets of goal-setting interventions are overlooked.

Despite the large number of studies, the validity of self-report measures of goal characteristics has not been systematically investigated for all available measures yet. Therefore, this project aims to develop new measures and validate a context-independent measure of 
multiple goal characteristics studied previously. This is important for at least three reasons. First, there are no studies evaluating the psychometric proprieties of a self-report measure that subsumes a broad range of goal characteristics that have previously been shown to be related to outcome variables such as goal achievement, motivational quality, real-world behaviors, and well-being (Milyavskaya \& Werner, 2018). Additionally, not all extant measures for individual measures have been validated. Second, it can provide a standard instrument by which goalsetting interventions can be evaluated, paving the way for a more practical knowledge base on the effects of such interventions. Third, the ability to characterize goals along a large set of dimensions can advance research on goal taxonomies. Therefore, the study aims to advance the measurement of important constructs for goal setting and goal pursuit.

The psychometric measures used so far show a number of shortcomings and limitations. Their reliability and validity are, in some cases, limited by a small number of items and missing empirical evidence for the correlation to latent variables (Milyavskaya \& Werner, 2018). The specificity of measures to a particular context is an additional limitation when comparing effects (e.g., comparing the impact of avoidance goals in educational, organizational, and personal goals). Therefore, evaluating their internal structure is an important step that has not yet been systematically investigated.

Some goal characteristics have been studied under ambiguous terms in achievement goal literature (Pintrich, 2000). This has led to studies concerned with disambiguation and clarification of constructs. For instance, "goal coherence", "goal integrity", and "goal congruence" are semantically related terms, which have been disentangled in a meta-analysis by Hulleman et al. (2010). Performance-approach goals are another example of a construct being operationalized inconsistently, according to Senko \& Dawson (2017). 
Some goal characteristics have been amalgamated in goal-setting research. The aforementioned performance-approach goals are a combination of the approach-avoidance characteristic and master-performance characteristic. In specific contexts, such a combination may lead to scientific insights, but such an entanglement may prevent the examination of essential subtleties with other goal characteristics. The aforementioned issues in existing measures can be overcome by providing clear empirical evidence of the dimensionality of goal characteristics and validity based on their relationship with other goal-related measures.

This paper describes the process of scale development and two studies conducted to provide evidence of validity on different levels. The paper is structured as follows. First, the development process is presented and the resulting scale structure of a self-report measure of many goal characteristics is established. Then two empirical studies are summarized. Study 1 was designed to evaluate the self-report questionnaire using exploratory and confirmatory factor analyses and provide evidence for validity based on the internal structure. Study 2 provides evidence of validity by examining correlations between dimensions of conceptually related constructs and dimensions of the proposed questionnaire. Lastly, the implications of the results are discussed, and important practical considerations for applied research are mentioned. Finally, the methodological potential of the GCQ to advance the goal-setting and motivation research is pointed out.

\section{Methodology used for Development and Refinement of the Initial GCQ}

The initial GCQ subscales and items were developed in an iterative process of extensive literature search, scale and item generation, evaluation by specialists, empirical evaluation and refinement. Because the focus was on goal-setting rather than on goal-pursuit, characteristics closely related to the latter, such as goal progress and monitoring, and goal-related emotions, 
such as regret and pride, were excluded. Other characteristics found in the goal-setting literature were excluded because of conceptual complexity (e.g., mastery-performance), contextdependence (e.g., proximal-distal), and relatedness to well-established motivational constructs (e.g., intrinsic-extrinsic). Considerations about these characteristics can be found in the discussion.

Before empirical evaluation of the first version of the questionnaire, the items were evaluated by two psychometricians, and ambiguous items were removed in an item-sort task (Anderson \& Gerbing, 1991). In order to assess the evidence of validity based on its internal structure, different measurement models were empirically evaluated in Study 1 using both a datadriven (exploratory graph analysis, EGA; Golino \& Epskamp, 2017) and a theoretically based approach (confirmatory factor analysis, CFA; Thompson, 2004). The results showed a theoretically and empirically robust structure, with 105 items and 27 factors, most of them invariant across different goal difficulties, time perspectives, and progress levels. Study 2 investigates evidence of validity based on correlations of GCQ factors with external measures such as different motivations (e.g., amotivation, extrinsic and intrinsic motivation) and goal commitment. In addition, the internal structure of the first version was improved regarding its reliability and invariance. Based on the findings, researchers can be encouraged to use the GCQ as a reliable tool to derive conclusions with robust validity in similar samples.

The final version of the GCQ measures 32 factors with 135 items. The 32 goal characteristics were grouped into five theoretical subscales, each containing constructs based on semantic similarity. Different subscale labels were iteratively created and regrouped until a consensus between the authors about the final structure was established, as shown in Table 1. 
Table 1

Hypothesized factor structure of the GCQ subscales.

\begin{tabular}{|c|c|c|c|c|c|}
\hline Structural & Framing & Attainability & $\begin{array}{c}\text { Resources } \\
\text { Availability }\end{array}$ & Interestingness & Usefulness \\
\hline $\begin{array}{l}\text { Content } \\
\text { Specificity }\end{array}$ & $\begin{array}{l}\text { Approach- } \\
\text { Avoidance }\end{array}$ & $\begin{array}{l}\text { Immediate } \\
\text { Actionability }\end{array}$ & $\begin{array}{l}\text { Social } \\
\text { Support }\end{array}$ & $\begin{array}{l}\text { Self- } \\
\text { Congruence }\end{array}$ & $\begin{array}{l}\text { Long-Term } \\
\text { Utility }\end{array}$ \\
\hline $\begin{array}{l}\text { Time } \\
\text { Specificity }\end{array}$ & $\begin{array}{r}\text { (Maintenance- } \\
\text { Attainment) }\end{array}$ & $\begin{array}{l}\text { Estimated } \\
\text { Effort }\end{array}$ & $\begin{array}{l}\text { Informational } \\
\text { Support } \\
\end{array}$ & $\begin{array}{l}\text { Value } \\
\text { Congruence }\end{array}$ & $\begin{array}{c}\text { Short-Term } \\
\text { Utility }\end{array}$ \\
\hline $\begin{array}{l}\text { Hierarchy - } \\
\text { High Level }\end{array}$ & $\begin{array}{l}\text { Process- } \\
\text { Outcome } \\
\text { Focus* } \\
\end{array}$ & Plannability & $\begin{array}{l}\text { Instrumental } \\
\text { Support }\end{array}$ & Importance & Relative Utility \\
\hline $\begin{array}{l}\text { Hierarchy - } \\
\text { Low Level }\end{array}$ & & Controllability & $\begin{array}{l}\text { Financial } \\
\text { Affordance }\end{array}$ & Awareness & $\begin{array}{l}\text { Self- } \\
\text { Improvement } \\
\text { Utility }\end{array}$ \\
\hline $\begin{array}{r}\text { Goal Network } \\
\text { Congruence }\end{array}$ & & Challenge & Visibility & (Attentiveness) & $\begin{array}{l}\text { Negative } \\
\text { Utility* }\end{array}$ \\
\hline Measurability & & $\begin{array}{l}\text { Defined } \\
\text { Subgoals }\end{array}$ & $\begin{array}{l}\text { Time } \\
\text { Availability }\end{array}$ & Vitality* & \\
\hline & & & $\begin{array}{l}\text { Competence } \\
\text { Adequacy }\end{array}$ & & \\
\hline
\end{tabular}

Note. * denotes factors included only in Study 2, “()" denotes factors that were excluded.

\section{Subscales and Goal Characteristics}

This section introduces the subscales which group semantically related goal

characteristics, the rationale behind each characteristic, and their importance for goal setting and pursuit is briefly summarized. We emphasize that the hierarchical theoretical structure does not reflect an empirical hierarchical latent structure to avoid misunderstandings. Instead, the subscales are intended to make it a theoretical organization of the 32 goal characteristics. The subscale structure does not imply that characteristics within one subscale necessarily correlate with each other. Neither it implies that, in applications where a subset of characteristics is measured, selecting a full subscale is more reasonable than picking characteristics from various subscales. Lastly, this questionnaire is not intended to be an exhaustive goal characteristic space covering the full range of goal characteristics that have been scientifically investigated. The remainder of this section describes the subscales and the goal characteristics that constitute them. 


\section{Structural Characteristics Subscale}

The structural characteristics subscale is, on the one hand, concerned with the precision of a goal's definition, including the specificity of its content and its intended time of achievement. On the other hand, it was designed to measure the relation of a goal to other goals in a goal system, such as their level in a hierarchy and congruence with each other. In sum, it covers six goal characteristics that are described as follows:

Content Specificity. Content specificity describes the degree of precision of the goal description. This characteristic has been shown to increase the probability of goal achievement (Locke et al., 1989). Goal specificity and its opposite, goal ambiguity, have been shown to predict public service motivation (PSM) in a study about motivation in the U.S. Federal Agencies (Jung \& Rainey, 2011).

Time Specificity. Time specificity describes how far the time frame for goal achievement is precisely defined. It has been found that deadlines for tasks increase the probability of task completion (Doran, 1981). In the concept of implementation intentions, a precise time for a task is defined, and a trigger event is specified (if-then plan), which increases the effectiveness of goals (Gollwitzer, 1999).

Measurability. Measurability describes how easily goal progress can be tracked. Measurability of progress is of significant relevance for monitoring goal progress and, consequently, goal achievement (Harkin et al., 2016). Monitoring goal progress is considered part of self-regulation and metacognition (e.g., Bjork et al., 2013). If an individual can measure the progress towards a goal or the distance towards a goal, effort and strategies can be adjusted to ensure goal achievement in time. 
Hierarchy- Low and High Level. These characteristics describe how much the goal is considered a low-level goal contributing to a higher-order goal or is the final desired state in itself that requires the achievement of subgoals. Based on a hierarchical structural organization, goals can be organized in different levels of abstraction, from describing a very abstract concept (e.g., "be goals") to precise motor sequences (e.g., "slice broccoli"; Carver \& Scheier, 2001). In the last decades, the study of goals as parts of goal systems with supportive or conflicting interrelations has become an emerging field of study (Kung \& Scholer, 2018, Ballard, Yeo, Loft, Vancouver, \& Neal, 2016; Kruglanski et al., 2002). The organization and control of behavior in hierarchical (goal-) structures has been debated, and there is substantial evidence to assume such representations (Cooper \& Shallice, 2006).

Goal Network Congruence. Network congruence quantifies the compatibility of a goal with other goals and goal systems. Goals have been investigated in isolation but also in relation to other goals (Louro et al., 2007) and goal systems (Kung \& Scholer, 2018). According to Kung and Scholer (2020), beneficial relations between goals have been studied as "goal facilitation" (Kruglanski et al., 2002; Riediger, 2007), "goal coherence”, or "goal integrity" (McGregor \& Little, 1998; Talevich, Read, \& Walsh, 2014).

\section{Framing Characteristics Subscale}

The framing subscale subsumes characteristics related to the perspective towards a goal, which is subjective and may change over time. A goal can be defined as avoiding versus approaching a state, maintaining a state versus attaining a state, and focusing on the process of goal pursuit versus focusing on the final goal. These are different ways of perceiving a goal, which have been demonstrated to affect our way of dealing with it. Those characteristics might be well suitable to assess the effects of interventions in a pre/post-test design since the end state 
of the goal does not need change. In sum, it covers three goal characteristics that are described as follows:

Approach-Avoidance Framing. Approach-avoidance framing describes whether the goal aims to avoid an aversive future state or approach the desired state. The distinction between approach and avoidance goals has emerged from the research on educational psychology (Elliot, 1999; Elliot \& McGregor, 2001; Miller, 1944; Elliot \& Thrash, 2001). Approach and avoidance orientation of goals moderate the effect of goal attainment on subjective well-being (Ehrlich, 2012).

Maintenance-Attainment Framing. Maintenance-attainment framing distinguishes goals that can be achieved and result in a stable achievement, such as completing a marathon, or goal states which have to be maintained, such as being sportive. Conceptually, maintenance goals can be seen as reference values or a standard, as outlined in the conceptual work by Boldero and Francis (2002). The General Approach, attainMent, Maintenance, and Avoidance (GAMMA) Motivation Scale (Lappi \& Wilkowski, 2020) measures this construct as stated in the name. This characteristic has been shown to impact perceived difficulty and goal choice (Stamatogiannakis et al., 2018).

Process vs. Outcome Focus. Outcome focus can be defined as the motivation for an activity because it is a means to a desirable end, whereas process focus is about the means (Sansone \& Thoman, 2005, Freund, Hennecke, \& Mustafić, 2012). In other words, the process vs. outcome focus characteristic describes whether the representation of a goal is focused on the means leading to the goal, such as climbing the mountain, or on the goal state or outcome, such as reaching the summit of a mountain. Studies found goal focus changes across adulthood, in which people shift from outcome- to process-focus with age (Hennecke, \& Mustafić, 2012). It 
has been shown that goal focus changes during action phases because the phases require a different perspective in terms of process and outcome (Freund, Hennecke, \& Mustafić, 2012).

\section{Attainability Characteristics Subscale}

The attainability subscales subsume constructs that are related to successful goal achievement. Many of the following characteristics can be related to the concept of S.M.A.R.T goals by Doran (1981), defined as specific, measurable, attainable, realistic, and time-related and originate from the management domain. In sum, it covers six goal characteristics that are described as follows:

Immediate Actionability. Immediate actionability measures the perceived height of the internal or external hurdle to act upon. It is closely related to the specificity of Doran's (1981) S.M.A.R.T goals. Planning strategies, such as implementation intentions (Gollwitzer, 1999), rely on this goal characteristic. Low scores in this characteristic may indicate a need for planning.

Estimated Effort. Estimated effort is intended to measure the amount of mental or physical effort the process of goal striving costs, approximated from the current point in time. The perceived effort may depend on other goal characteristics. For example, a hard task for a goal with high self-congruence may feel less demanding than an easy task for a goal with low self-congruence. Subjective ease has been shown to benefit goal progress (Werner et al., 2016).

Plannability. Plannability measures to which extent the steps towards goal pursuit are foreseeable. This aspect of goal setting is essential for estimations about the duration, effort, and circumstances of goal achievement. People tend to concentrate their time planning on the near future (Lynch et al., 2010). Therefore, plannability can be an elementary target for most inventions. Perceived low plannability does not necessarily indicate a factual low plannability, but the opposite: low scores for this characteristic may indicate a lack of planning. 
Controllability. Controllability quantifies the degree to which a person perceives the locus of control for a specific goal within himself versus the environment. Certainly, some goals lie beyond one's control, such as winning a lottery or having good weather tomorrow. For most of the goals humans have, they also have control. Personality psychology has studied how people perceive causality for a long time (Russell, 1982; Crafts \& Rotter, 1955), so trait factors may influence this goal characteristic. For example, locus of control is a trait variable that reflects the degree to which a person believes the control about events in their life lies within or outside himself. Locus of control is a strong predictor of attitudes, motivation, and behavior (Galvin et al., 2018). Intuitively, a necessary prerequisite for taking an action towards a goal is a belief in the control over the outcome; however, belief alone is insufficient.

Challenge. The goal property of challenge has already been investigated early in the history of goal setting. Locke and Latham (1991) postulated in their goal-setting theory that the perceived challenge of a goal correlates positively to performance (Lunenburg, 2011), as long as the limit of perceived ability is not exceeded. Above this point, productivity drops due to hopelessness to reach the goal (Latham \& Locke, 1991).

Defined Subgoals. The number of defined subgoals is the operationalization of the degree to which a plan for goal achievement has been established and can be described with a set of subgoals, possibly in a logical order. In practice, it can measure the degree to which a plan for goal pursuit has already been explicitly determined or how far it needs to be done. The study of multiple goals instead of isolated goals is an emerging field (see, for instance, Louro et al., 2007, which is the motivation for the authors to introduce this subscale). 


\section{Resources Availability Characteristics Subscale}

The resources availability subscale assesses the degree of presence of facilitators for goal pursuit. Semantically, the characteristics from this scale are related to the attainability characteristics. For example, goals with sparse or unavailable crucial resources probably result in high scores for the challenge characteristic and low scores for the immediate actionability characteristic. The separation into two separate subscales was motivated to distinguish characteristics based on the resource-related nature. The diversification of resource availability has high practical relevance because lacking support for goal pursuit may result in compensation strategies or goal abandonment. The characteristics in this scale were also inspired by the job demands-resources model, which aims to explain job engagement, which the authors assume to be close to goal commitment, based on job demands and a set of resources (Demerouti \& Bakker, 2011). In sum, this subscale covers seven goal characteristics that are described as follows:

Social Support. The characteristic of social support quantifies the degree of perceived support in the social environment to attain a goal. In the educational context, it has been shown that perceived social support can positively affect motivation and achievement (Song et al., 2015).

Informational Support. Informational support is the availability of information necessary for successful goal pursuit. Informational support has been investigated as a part of social support (Malecki \& Demaray, 2003). It plays a central role in educational contexts where the acquisition of knowledge, skills, and competencies strongly rely on the availability of information. 
Instrumental Support. Instrumental support is the availability of equipment and materials required for successful goal pursuit. It is reasonable to assume that the (perceived) availability of required materials is a necessary precondition for goal pursuit. The creation of subgoals or withdrawal might compensate for a lack of instrumental support. Instrumental support has also been investigated as a part of social support (Malecki \& Demaray, 2003).

Financial Affordance. Financial affordance is the availability of monetary resources required for goal pursuit. As such, it is a specific aspect of instrumental support that can affect goal-setting. For example, the financial affordance of health care services can impact treatment options (e.g., Ren et al., 2019) and, therefore, impact if and how people pursue their healthrelated goals.

Visibility. Visibility is the characteristic of a goal being visible by the social environment. Visibility is considered a resource since public commitment to a goal improves goal commitment (Locke \& Latham, 2002). On the other hand, public visibility of identityrelated behavioral intentions can decrease the respective behavior caused by the premature sense of possessing the desired identity and decreasing effort to attain it (Gollwitzer et al., 2009). Therefore, visibility can unfold positive effects by increasing commitment to a goal. Still, visibility can be counterproductive, especially for identity-related goals, because it leads to rewarding experiences before the goal is reached. Furthermore, the social status of the audience knowing about a goal was found to be positively correlated to goal commitment (Klein et al., 2020).

Time Availability. Time availability measures the degree to which the time required to pursue a goal is available. Limited temporal resources are a crucial limitation of goal pursuit and prioritization. Goal selection and goal disengagement are strategies suitable to deal with it. Time- 
relatedness is traditionally an essential aspect of effective goal setting (Doran, 1981). In sum, time is a valuable finite resource whose allocation should be considered during goal selection and pursuit (e.g., Wrosch et al., 2003).

Competence Adequacy. Competence adequacy is a characteristic related to the required skills for the person having the goal. If a goal is perceived as far below one's capabilities, it may be easy to achieve but may be perceived as not challenging. On the other hand, goals being far above one's competencies may be perceived as overwhelming, leading to decreased activity and motivation (Latham \& Locke, 1991). The goal characteristic of competence adequacy is closely related to self-efficacy (Bandura, 1977), defined as the belief in one's own competence to achieve one's goals, and positively affects health and effectiveness (Bandura, 1982; 1997).

\section{Interestingness Characteristics Subscale}

The interestingness subscale subsumes variables related to the subjective relevance of goals. Although the intrinsic-extrinsic motivational continuum is not directly covered in the GCQ, the characteristics of this subscale may be suitable to predict it. Most of the constructs of this subscale have been studied in positive psychology and have been shown to positively affect well-being. In sum, it covers five goal characteristics that are described as follows:

Self-Congruence. Self-congruence or self-concordance is the degree to which a goal is perceived to be aligned to the person's self-concept or identity. Self-congruence can also be related to the self-determination continuum (SDC; Ryan \& Deci, 2000) to measure the degree to which a goal is internalized. Evaluating a goal's self-congruence can help people identify a more intrinsic selection (Sheldon et al., 2019). In addition, it has been shown in a meta-analysis that self-concordance positively correlates with goal progress (Koestner, Lekes, Powers, \& Chicoine, 2002). 
Value Congruence. Value congruence is the degree to which a goal aligns with one's beliefs, values, dreams, and ideal self. Value congruent goals are associated with the experience of meaning in life (McGregor \& Little, 1998). They are a marker of approach motivation and resource for goal pursuit, especially under uncertainty, anxiety, and threat (McGregor et al., 2013).

Importance. The importance characteristic measures the personal relevance of a goal. In situations of goal prioritization, this characteristic may be helpful to determine which goals to drop. Importance is a commonly used goal characteristic and closely related to goal commitment. Vancouver and Austin (1996) have identified importance-commitment as one of six factors found across a broad range of empirical and theoretical goal dimensions.

Awareness. Awareness is the degree to which a goal has been conscious prior to the time of measurement. It has been demonstrated that goal pursuit can originate and work in the unconscious level, and even behavior control is possible without conscious awareness (Bargh et al., 2001; Aarts, Custers, \& Veltkamp, 2008). Awareness can moderate the relationship between goal progress and well-being under certain conditions (Pomaki, Karoly, \& Maes, 2009). In social contexts, goal contagion arises when humans adopt goals implied by the behavior of others (Aarts, Gollwitzer, \& Hassin, 2004). For the investigation of this and related phenomena, awareness is of relevance. In Study 1, the characteristic was named attentiveness, which turned out not to be precise because attention is a process that does not require awareness (Dijksterhuis \& Aarts, 2010), hampering the development of a self-report measure.

Vitality. Closely related to the construct of absorption in the engagement literature (Wefald \& Downey, 2009), vitality measures a positive affection in a person elicited by their goal representation. This variable is a desirable goal characteristic per se, especially from the 
perspective of positive psychology. Additionally, it has been found to be a predictor of goal progress (Hope et al., 2016).

\section{Usefulness Characteristics Subscale}

The usefulness subscale includes variables of utility a goal may have. The variables of this subscale are intended to uncover positive and negative rewards on different temporal horizons as a result of pursuing the goal in question. These characteristics might be especially relevant for the selection of conscious goals. For example, moral utility theory suggests that (un-)ethical decisions are based on a trade-off between different aspects of utility (Hirsh et al., 2018), which might directly affect the selection of altruistic goals. Moreover, subjective evaluations of direct and indirect outcomes might affect goal selection and pursuit differently depending on other goal characteristics and the person's traits and abilities, such as cognitive control. In sum, it covers five forms of goal characteristics expressing usefulness that are described as follows:

Long-Term Utility. Long-term utility is the property of goals leading to rewards in the far future. The long-term utility of a goal is relevant in goal-setting interventions because humans naturally tend to prefer short-term utility of actions or goals over long-term utility in the early stages of their development. This ability to choose actions with high long-term utility and low short-term utility is a skill that has been investigated under the key term of time-perspective in positive psychology (Boniwell \& Zimbardo, 2012).

Short-Term Utility. Short-term utility is the property of goals leading to rewards in the near future. Balancing time perspectives and overcoming the temptations of immediate benefits has been considered a key to a good life by positive psychologists (Boniwell \& Zimbardo, 2012). 
For example, interindividual differences in weighting immediate and distant outcomes of actions are highly relevant for a range of health problems (Strathman et al., 1994).

Relative Utility. Relative utility is the degree to which pursuing a goal leads to rewards in comparison to other goals. Humans tend to have more goals than they can possibly pursue with their limited amounts of resources (Neal et al., 2017, Kung \& Scholer, 2020), so they have to decide on which goal to commit to. Multiple goal pursuit is an emerging field of research (Kung \& Scholer, 2020) in which this goal characteristic may be applied.

Self-Improvement Utility. Self-improvement utility quantifies the degree to which the process of goal pursuit is expected to lead to personal growth or the development of new abilities or insights. This characteristic is conceptually related to "learning goals", which are opposed to "performance goals" in educational psychology (Bouffard, Boisvert, Vezeau, \& Larouche, 1995). Growth goals have been shown to predict subjective well-being (SWB) in the future (Bauer \& McAdams, 2010) and goals about eudaimonic functioning have been shown to have the tendency to succeed (Sheldon, et al., 2019). Moreover, self-improvement motivation is a relevant motivational tendency in the domain of metacognition (Jiang \& Kleitman, 2015).

Negative Utility. Negative utility is a measure of the degree to which achieving a goal leads to aversive consequences. Negative utility is a relevant feature of goals since most of them have both positive and negative consequences. In addition, appetite and aversive motivation elicit distinct neural processes and, consequently, behavioral responses (Yee et al., 2021). This characteristic arose from separating the reverse coded items of the utility characteristic from the positively formulated items in the second (see results section of Study 2). The alternative models of the CFA showed a better fit for a model treating the negative items as belonging to a distinct factor. 
To assess the validity of the GCQ, two studies were conducted and reported in the following two sections. The first study was conducted to measure and improve the internal validity by exploratory and confirmatory factor analyses. The second study was conducted to provide evidence of concurrent validity based on comparisons with established measures.

\section{Study 1: Evidence of Validity Based on Internal Structure}

Our first study aimed to evaluate the evidence of validity based on the internal structure of the questionnaire developed so far and to refine its subscales and items. The analyses of Study 1 aim at testing the internal validity using an exploratory and a confirmatory approach of factor analysis for each subscale. The final measurement models show good fit and reliability indices.

\section{Methods}

\section{Participants}

A sample of 600 participants was invited to participate in a study about personal goals via Positly, a web-based research platform, for a compensation of $\$ 2.00$ for a study lasting approximately 15 minutes. Of those, 590 participants completed the survey and the results were included in the analysis ( $52 \%$ female; average age $=40$ years, $S D=12$ years). To be allowed to participate in the study, participants had to report to hold US citizenship, be fluent in English and be above 18 years old.

\section{Measures}

The first version of the questionnaire was subdivided into the five subscales structural, attainability, resource availability, interestingness, and usefulness, measuring 27 latent variables with 171 items. Participants rated their agreement with them using a five-point scale with levels ranging from 1 ("strongly disagree") to 5 ("strongly agree"). Participants also responded to three 
self-report questions about when they set the goal, its expected time perspective for achievement, difficulty, and stage (for a full description of these measures, see the Supplementary Material, Sections 4 and 5).

\section{Procedure}

Participants were invited to an online study about personal goals and filled out a consent form prior to the experiment. In order to increase variability, participants were instructed to think about individual goals according to one of the randomly assigned prompts, which were validated in a pilot study (see Supplementary Material, Section 1). The prompts varied in a betweensubjects design. Depending on the condition, participants were asked to report on goals at different progress levels ("accomplished or almost accomplished (>75\%)", "made considerable progress (50-75\%)", "some progress (25-49\%)", "little progress or just started $(<25 \%)$ ), "gave up"); time perspective ("today", "this month" and "this year"); and difficulty (“easy" and "hard"). A graphical scale of progress from 0-100\% accompanied the prompts to help participants interpret the progress prompts. As an example of prompt: "Think about a goal that you intended to achieve this month that you have already given up and you thought it would be hard to complete it."

Following the prompt, participants were asked to write about their goal and about the reason why they were pursuing it. Next, participants answered the self-report measures regarding the chosen goal. Afterward, participants answered the GCQ. The order of the GCQ items was randomized across participants. Lastly, participants answered socio-demographic questions (see Supplementary Material, Section 2, for details about the elicitation procedure). This study has been approved by the $\{$ masked for review . 


\section{Data Analysis}

Because participants were required to answer all questions, all data sets were complete, and no participants were excluded from the analysis. To investigate the dimensionality of the observed variables, an exploratory graph analysis (EGA; Golino \& Epskamp, 2017) was conducted for each subscale. EGA is a network-analysis approach to estimate the number of dimensions to retain. According to the structure suggested by EGA, we modified the hypothesized model, changing or excluding items with non-predicted relations. Then, confirmatory factor analysis (CFA) was conducted with the diagonal weight least square estimator (Li, 2016) to compare the fit for this modified structure with alternative models. For each subscale, fit indices from the null, unifactorial, hypothesized, EGA, and modified models were compared. In order to compare the effect of conditions, a measurement invariance analysis and a subsequent MANOVA were conducted with the invariant factors across the conditions. All analyses were conducted in R v. 3.6.1 (R Core Team, 2016), using lavaan and EGAnet packages (Rosseel, 2012; Hirschfeld \& Brachel, 2019; Golino et al., 2021). Raw data is available at Authors (2021; see references for full link).

\section{Results}

\section{Factor Structure}

Table 2 shows the fit for alternative models for each subscale. Hypothesized structural, resource availability, and interestingness models did not show an acceptable fit. All hypothesized models were modified based on modification indices, error covariance between items and theoretically incongruent solutions indicated by the EGA model. The modified models of each subscale showed a good fit $(\mathrm{CFI} \geq 0.96$, TLI $\geq 0.95$, RMSEA $\leq 0.05$, SRMR $\leq 0.06)$. 
Table 2

Fit indices for alternative measurement models for each subscale.

\begin{tabular}{|c|c|c|c|c|c|c|c|}
\hline Model & $\chi^{2}$ & df & CFI & TLI & RMSEA & SRMR & ECVI \\
\hline \multicolumn{8}{|l|}{ Structural } \\
\hline Null & 12909 & 741 & 0.00 & 0.00 & 0.17 & 0.20 & 22.05 \\
\hline Unifactorial & 7964 & 702 & 0.55 & 0.53 & 0.12 & 0.13 & 10.36 \\
\hline Hypothesized & 3953 & 687 & 0.80 & 0.79 & 0.08 & 0.09 & 5.27 \\
\hline EGA & 2633 & 725 & 0.89 & 0.88 & 0.06 & 0.07 & 3.51 \\
\hline Modified & 662 & 254 & 0.96 & 0.96 & 0.04 & 0.05 & 0.93 \\
\hline Hierarchical & 2127 & 268 & 0.80 & 0.77 & 0.09 & 0.10 & 2.79 \\
\hline Model & $\chi^{2}$ & df & CFI & TLI & RMSEA & SRMR & ECVI \\
\hline \multicolumn{8}{|l|}{ Attainability } \\
\hline Null & 16197 & 780 & 0.00 & 0.00 & 0.18 & 0.21 & 27.64 \\
\hline Unifactorial & 7677 & 740 & 0.69 & 0.67 & 0.11 & 0.12 & 9.38 \\
\hline Hypothesized & 3973 & 725 & 0.85 & 0.84 & 0.07 & 0.08 & 5.04 \\
\hline EGA & 4601 & 979 & 0.87 & 0.86 & 0.07 & 0.08 & 5.83 \\
\hline Modified & 826 & 284 & 0.96 & 0.95 & $\overline{0.05}$ & 0.06 & 1.11 \\
\hline Hierarchical & 1643 & 293 & 0.89 & 0.88 & 0.07 & 0.08 & 2.06 \\
\hline \multicolumn{8}{|c|}{ Resource Availability } \\
\hline Null & 15049 & 595 & 0.00 & 0.00 & 0.20 & 0.25 & 25.67 \\
\hline Unifactorial & 3005 & 405 & 0.86 & 0.85 & 0.08 & 0.09 & 3.11 \\
\hline Hypothesized & 2504 & 545 & 0.92 & 0.92 & 0.06 & 0.07 & 2.67 \\
\hline EGA & 1080 & 367 & 0.97 & 0.96 & 0.04 & 0.06 & 1.20 \\
\hline Modified & 532 & 215 & 0.98 & 0.97 & 0.04 & 0.05 & 0.68 \\
\hline Hierarchical & 863 & 224 & 0.95 & 0.94 & 0.05 & 0.06 & 1.03 \\
\hline \multicolumn{8}{|l|}{ Interestingness } \\
\hline Null & 12310 & 528 & 0.00 & 0.00 & 0.20 & 0.23 & 21.01 \\
\hline Unifactorial & 3719 & 495 & 0.82 & 0.81 & 0.09 & 0.10 & 4.36 \\
\hline Hypothesized & 3491 & 489 & 0.83 & 0.82 & 0.08 & 0.09 & 4.11 \\
\hline EGA & 2745 & 485 & 0.88 & 0.86 & 0.07 & 0.08 & 3.30 \\
\hline Modified & 286 & 98 & 0.97 & 0.97 & 0.04 & 0.05 & 0.39 \\
\hline Hierarchical & 379 & 115 & 0.96 & 0.96 & 0.05 & 0.06 & 0.49 \\
\hline \multicolumn{8}{|l|}{ Usefulness } \\
\hline Null & 11261 & 253 & 0.00 & 0.00 & 0.27 & 0.31 & 19.20 \\
\hline
\end{tabular}




\begin{tabular}{lccccccc}
\hline Unifactorial & 1444 & 230 & 0.95 & 0.94 & 0.07 & 0.08 & 1.35 \\
\hline Hypothesized & 1280 & 224 & 0.95 & 0.95 & 0.06 & 0.07 & 1.22 \\
\hline EGA & 821 & 224 & 0.97 & 0.97 & 0.05 & 0.06 & 0.84 \\
\hline Modified & $\mathbf{2 6 8}$ & $\mathbf{8 4}$ & $\mathbf{0 . 9 9}$ & $\mathbf{0 . 9 8}$ & $\mathbf{0 . 0 4}$ & $\mathbf{0 . 0 5}$ & $\mathbf{0 . 3 1}$ \\
\hline Hierarchical & 266 & 86 & 0.99 & 0.98 & 0.04 & 0.05 & 0.30 \\
\hline
\end{tabular}

Note. The null model represents no covariance between observed variables. The EGA models were specified by a network approach to determine the dimensionality. The hypothesized model was defined based on the construction of the items. The modified model was defined based on the modification indices and the theoretically consistent structures indicated by EGA. The hierarchical model tested a hierarchical structure of the modified version with a single hierarchical factor. $\chi^{2}=$ Chi-Square with Satorra-Bentler correction; $\mathrm{df}=$ degrees of freedom; $\mathrm{CFI}=$ comparative fit index; TLI = Tucker Lewis index; RMSEA = root mean square error of approximation; $\mathrm{SRMSR}=($ standardized $)$ root mean square residual; ECVI $=$ expected crossvalidation index.

Table 3-7 show the loading coefficients and reliability for each subscale for the final version. Although most of the factors show good reliability $(\alpha>.70)$ and medium to high loading coefficients $(\lambda>.60)$, some of the factors did not show acceptable indices. Interfactor correlations showed great variability of relationships between the goal characteristics $\left(M_{|r|}=.42\right.$, $S D_{|r|}=.27$ ). However, from the 351 interfactor correlations (see Supplementary Material, Section 7), eight were high $(|r| \geq .90)$, indicating a great overlap between some constructs. 
Table 3

Standardized loading coefficients ( $\lambda$ ) and Cronbach's $\alpha$ reliability for the structural subscale.

\begin{tabular}{cccccccccccccc}
\hline $\begin{array}{c}\text { Content } \\
\text { Specificity } \\
(\alpha=.49)\end{array}$ & $\begin{array}{c}\text { Time } \\
\text { Specificity } \\
(\alpha=.81)\end{array}$ & $\begin{array}{c}\text { Hierarchy - } \\
\text { High Level } \\
(\alpha=.59)\end{array}$ & $\begin{array}{c}\text { Hierarchy - } \\
\text { Low Level } \\
(\alpha=.81)\end{array}$ & $\begin{array}{c}\text { Network } \\
\text { Congruence } \\
(\alpha=.80)\end{array}$ & $\begin{array}{c}\text { Measurability } \\
(\alpha=.78)\end{array}$ & $\begin{array}{c}\text { Avoidance } \\
\text { Framing } \\
(\alpha=.71)\end{array}$ \\
\hline Item & $\lambda$ & Item & $\lambda$ & Item & $\lambda$ & Item & $\lambda$ & Item & $\lambda$ & Item & $\lambda$ & Item & $\lambda$ \\
\hline 1 & .424 & 8 & .703 & 16 & .664 & 14 & .744 & 21 & .747 & 28 & .682 & 35 & .777 \\
\hline 2 & .619 & 9 & .778 & 20 & .628 & 13 & .757 & 25 & .771 & 29 & .597 & 38 & .527 \\
\hline 19 & .486 & 10 & .756 & 18 & .418 & 15 & .806 & 26 & .736 & 30 & .686 & 39 & .700 \\
\hline & 11 & .654 & & & & & & & 31 & .695 & 40 & .471 \\
\hline
\end{tabular}

Table 4

Standardized loading coefficients ( $\lambda$ ) and Cronbach's $\alpha$ reliability for the attainability subscale.

\begin{tabular}{|c|c|c|c|c|c|c|c|c|c|c|c|}
\hline \multicolumn{2}{|c|}{$\begin{array}{c}\text { Immediate } \\
\text { Actionability } \\
(\alpha=.71)\end{array}$} & \multicolumn{2}{|c|}{$\begin{array}{c}\text { Required } \\
\text { Effort } \\
(\alpha=.71) \\
\end{array}$} & \multicolumn{2}{|c|}{$\begin{array}{c}\text { Plannability } \\
(\alpha=.70)\end{array}$} & \multicolumn{2}{|c|}{$\begin{array}{c}\text { Controllability } \\
\quad(\alpha=.73)\end{array}$} & \multicolumn{2}{|c|}{$\begin{array}{c}\text { Challenge } \\
(\alpha=.79)\end{array}$} & \multicolumn{2}{|c|}{$\begin{array}{c}\text { Defined } \\
\text { Subgoals } \\
(\alpha=.61) \\
\end{array}$} \\
\hline Item & $\lambda$ & Item & $\lambda$ & Item & $\lambda$ & Item & $\lambda$ & Item & $\lambda$ & Item & $\lambda$ \\
\hline 51 & .562 & 85 & .501 & 92 & .618 & 104 & .569 & 113 & .547 & 168 & .684 \\
\hline 52 & .535 & 86 & .771 & 93 & .615 & 105 & .561 & 116 & .750 & 169 & .623 \\
\hline 53 & .621 & 87 & .717 & 95 & .602 & 107 & .479 & 117 & .630 & 170 & .459 \\
\hline 54 & .637 & & & 97 & .597 & 108 & .508 & 118 & .659 & & \\
\hline \multirow[t]{2}{*}{55} & .570 & & & & & 109 & .620 & 119 & .668 & & \\
\hline & & & & & & 111 & .592 & & & & \\
\hline
\end{tabular}


Table 5

Standardized loading coefficients ( $\lambda$ ) and Cronbach's a reliability for resource availability subscale.

\begin{tabular}{|c|c|c|c|c|c|c|c|c|c|c|c|}
\hline \multicolumn{2}{|c|}{$\begin{array}{c}\text { Social } \\
\text { Support } \\
(\alpha=.67) \\
\end{array}$} & \multicolumn{2}{|c|}{$\begin{array}{c}\text { Informational } \\
\text { Support } \\
(\alpha=.70) \\
\end{array}$} & \multicolumn{2}{|c|}{$\begin{array}{c}\text { Instrumental } \\
\text { Support } \\
(\alpha=.75) \\
\end{array}$} & \multicolumn{2}{|c|}{$\begin{array}{c}\text { Financial } \\
\text { Affordance } \\
(\alpha=.82)\end{array}$} & \multicolumn{2}{|c|}{$\begin{array}{c}\text { Time } \\
\text { Availability } \\
(\alpha=.73)\end{array}$} & \multicolumn{2}{|c|}{$\begin{array}{c}\text { Competence } \\
\text { adequacy } \\
(\alpha=.79)\end{array}$} \\
\hline Item & $\lambda$ & Item & $\lambda$ & Item & $\lambda$ & Item & $\lambda$ & Item & $\lambda$ & Item & $\lambda$ \\
\hline 63 & 0.659 & 69 & 0.634 & 75 & 0.644 & 80 & 0.777 & 56 & 0.716 & 98 & 0.706 \\
\hline 64 & 0.546 & 70 & 0.590 & 76 & 0.723 & 82 & 0.668 & 57 & 0.673 & 100 & 0.778 \\
\hline \multirow[t]{3}{*}{65} & 0.715 & 71 & 0.636 & 77 & 0.572 & 83 & 0.896 & 58 & 0.535 & 101 & 0.556 \\
\hline & & 72 & 0.529 & 78 & 0.639 & & & 60 & 0.640 & 102 & 0.610 \\
\hline & & & & & & & & & & 103 & 0.731 \\
\hline
\end{tabular}

Table 6

Standardized loading coefficients ( $\lambda)$ and Cronbach's $\alpha$ reliability for interestingness subscale.

\begin{tabular}{cccccccc}
\hline $\begin{array}{c}\text { Self-Congruence } \\
(\alpha=.56)\end{array}$ & \multicolumn{2}{c}{$\begin{array}{c}\text { Value Congruence } \\
(\alpha=.79)\end{array}$} & \multicolumn{2}{c}{$\begin{array}{c}\text { Importance } \\
(\alpha=.78)\end{array}$} & \multicolumn{2}{c}{$\begin{array}{c}\text { Awareness } \\
(\alpha=.71)\end{array}$} \\
\hline Item & $\lambda$ & Item & $\lambda$ & Item & $\lambda$ & Item & $\lambda$ \\
\hline 129 & 0.661 & 125 & 0.678 & 139 & 0.637 & 41 & 0.460 \\
\hline 124 & 0.384 & 126 & 0.636 & 143 & 0.679 & 42 & 0.637 \\
\hline 121 & 0.432 & 128 & 0.748 & 132 & 0.699 & 43 & 0.685 \\
\hline & & 131 & 0.734 & 134 & 0.606 & 47 & 0.675 \\
\hline
\end{tabular}


Table 7

Standardized loading coefficients ( $\lambda$ ) and Cronbach's $\alpha$ reliability for usefulness subscale.

\begin{tabular}{cccccccc}
\hline $\begin{array}{c}\text { Long-Term Utility } \\
(\alpha=.84)\end{array}$ & $\begin{array}{c}\text { Short-Term Utility } \\
(\alpha=.60)\end{array}$ & $\begin{array}{c}\text { Relative Utility } \\
(\alpha=.70)\end{array}$ & $\begin{array}{c}\text { Self-Improvement } \\
\text { Utility } \\
(\alpha=.70)\end{array}$ \\
\hline Item & $\lambda$ & Item & $\lambda$ & Item & $\lambda$ & Item & $\lambda$ \\
\hline 144 & 0.786 & 150 & 0.405 & 156 & 0.607 & 164 & 0.649 \\
\hline 145 & 0.615 & 152 & 0.654 & 157 & 0.493 & 165 & 0.560 \\
\hline 148 & 0.801 & 154 & 0.688 & 158 & 0.629 & 166 & 0.809 \\
\hline 149 & 0.808 & 151 & 0.344 & 159 & 0.696 & & \\
\hline
\end{tabular}

Scalar Invariance: Effect of Conditions on Factor Scores

Before comparing factor scores between conditions, the authors tested the measures' scalar invariance to different time perspectives, difficulties, and levels of progress independently. Scalar invariance refers to the equivalence of the structure, intercepts, and loading coefficients across groups. Investigating scalar invariance is necessary to be able to adequately compare differences between the means of latent variables (Chen, 2007). To test for scalar invariance, the authors estimated models constraining the factor structure, loadings, and thresholds to be equal across one of the conditions (difficulty, time perspective, and progress) using the delta parametrization (Millsap \& Yun-Tein, 2004). Compared with the unconstrained models, the fit indices of the constrained models did not decrease above the thresholds of $\Delta \mathrm{CFI}<-.01$, $\triangle \mathrm{RMSEA}>.015$, and $\triangle \mathrm{SRMR}>.015$ (Chen, 2007; Cheung \& Rensvold, 2002), except for usefulness factors across different levels of progress. For usefulness factors, fit indices for the model constraining loading coefficients (metric invariance) were above the threshold, $\Delta \mathrm{CFI}=$ $-.011, \triangle \mathrm{RMSEA}=.019$, and $\triangle \mathrm{SRMR}=.020$. These results suggest that scalar invariance can be assumed across time perspectives, difficulty, and progress, except that usefulness factors are not 
invariant across different levels of progress. Since usefulness was not invariant across progress conditions, latent mean differences were tested without usefulness factors (Long-Term, ShortTerm, Relative, and Self-Improvement Utility). For detailed fit indices of configural, metric, and scalar models across conditions, see Supplementary Material, Section 8.

Mean differences in the factor scores were expected across the prompt conditions (time perspective, difficulty, and progress) without specific hypotheses. Therefore, the authors conducted exploratory analyses for direct and interaction effects of the conditions using a MANOVA. As shown in T0able 8, all direct effects were statistically significant, but no interaction effects were significant at a corrected alpha level using a Sidak's correction for seven comparisons $(\alpha=0.0073)$.

Table 8

Multivariate statistics for direct and interaction effects of the conditions on GCQ factor scores.

\begin{tabular}{lccccccc}
\hline \multicolumn{1}{c}{ Effect } & $\boldsymbol{d f}$ & $\begin{array}{c}\text { Pillai's } \\
\text { Trace }\end{array}$ & $\boldsymbol{F}(\mathbf{d f 1}$, & $\mathbf{d f 2})$ & $\boldsymbol{F}$ & $\boldsymbol{p}$ & $\boldsymbol{\eta p}^{\mathbf{2}}$ \\
\hline Progress & 4 & 0.301 & 92 & 2164 & 1.91 & $<.0001$ & .075 \\
\hline Time Perspective & 2 & 0.322 & 46 & 1078 & 4.49 & $<.0001$ & .160 \\
\hline Difficulty & 1 & 0.137 & 23 & 538 & 3.72 & $<.0001$ & .137 \\
\hline Progress $\times$ Time Perspective & 8 & 0.329 & 184 & 4360 & 1.02 & .42 & .041 \\
\hline Progress $\times$ Difficulty & 4 & 0.218 & 92 & 2164 & 1.36 & .02 & .055 \\
\hline Time Perspective $\times$ Difficulty & 2 & 0.086 & 46 & 1078 & 1.05 & .38 & .043 \\
\hline $\begin{array}{l}\text { Progress } \times \text { Time Perspective } \times \\
\text { Difficulty }\end{array}$ & 8 & 0.286 & 184 & 4360 & 0.88 & .87 & .036 \\
\hline Residuals & 560 & & & & & & \\
\hline
\end{tabular}

Post-hoc analyses for univariate effects were conducted and reported in the Supplementary Material (Section 9). When correcting for multiple comparisons, the results show that Time Availability, Estimated Effort, Plannability, Competence Adequacy, and Challenge 
factors scores changed across difficulty conditions. For time perspective, factors scores were significantly different for Time Specificity, High Hierarchy, Instrumental Support, Financial Affordance, Competence Adequacy, Challenge, Value Congruence, and Importance changed across time perspective conditions. Regarding the progress condition, the results show differences in Content Specificity, Time Specificity, Measurability, Immediate Actionability, Time Availability, Social Support, Informational Support, Plannability, Competence Adequacy, Controllability, Defined Subgoals, Self-Congruence and Importance. In general, progress prompts showed quantitatively more univariate effects, while time perspective prompts showed a larger multivariate effect size. To conclude, these effects show additional support for the effect of the prompts (see also Section 1 of the Supplementary Material).

\section{Discussion}

This study aimed to investigate the evidence of validity based on the internal structure of the GCQ. The EGA method allowed us to compare the hypothesized or intended factor structure with exploratory data-driven models. The hypothesized measurement model was improved by modifications based on local and global misfits in the models. Although the modified measurement models show a good fit, a few factors show low loading coefficients and reliability indices (e.g., Content Specificity, High Hierarchy, Defined Subgoals, Self-Congruence, and Short-Term Utility). The Structural, Attainability, Resources Availability, and Interestingness measurement models were invariant across all prompt conditions, allowing the comparison of several goal characteristics regardless of their goal progress, time perspective, and difficulty. However, the usefulness subscale was not invariant across progress conditions, hindering the possibility to compare usefulness factors means if goals diverge in their progress levels. In 
addition, a high correlation between some factors was observed (see Supplementary Material, Section 8). However, theoretical differences between the constructs might not have been captured by the current pool of items. Therefore, the GCQ was modified in Study 2 to overcome these limitations.

Notably, the effects of the conditions were consistent with logical assumptions. For example, goals that were almost complete are more specific regarding their content and time of achievement. They were also more attainable - there are more time available to work on their goals, they are more plannable, more controllable, more immediate actionable, and they have more defined subgoals. Goals with longer time perspectives are perceived to have a less defined time to be achieved, to be more higher-level, challenging, value-congruent, and important. In addition, people perceive to have less competence, financial and instrumental resources to achieve them. Hard goals are perceived to be more challenging, require more effort, be less plannable, and be less adequate to people's competence.

The questionnaire was improved based on these results for the next study. Items were added for factors with low reliability and non-invariance across conditions. In addition, items for new hypothesized factors were added: Process-Outcome Framing, Maintenance-Attainment Framing, Vitality, Visibility, and Negative Utility. The final version measures 32 latent variables using 135 items (see Supplementary Material, Section 5). As discussed later, the resulting version of the GCQ shows good evidence of validity based on its internal structure and related measures. 


\section{Study 2: Evidence of Validity Based on Related Measures}

The goal of Study 2 was to show concurrent validity of the GCQ, which is relevant because there are well-established measures for central constructs in motivational research, to which the GCQ should be compatible and comparable. While Study 1 has shown that the items of each dimension measure some common latent variable, Study 2 demonstrates that GCQ factors are correlated to constructs that are theoretically relevant to them. In practice, this is achieved by showing positive and negative correlations to well-established measures in the field. The authors agreed on a list of hypotheses about positive and negative correlations between latent variables of the GCQ and latent variables of other measures that should hold from a conceptual perspective. Additionally, the GCQ was examined regarding its reliability, discriminability between factors, and invariance across conditions.

\section{Methods}

\section{Participants}

Volunteers were invited to participate in an online study about personal goals via Positly. Participants were compensated with $\$ 4.00$ for an estimated 30 min study $(M=29.44 \mathrm{~min}, S D=$ $14.2 \mathrm{~min})$. A total of 515 participants completed the study. Thirty-three participants who failed to provide a valid goal were excluded. In addition, six participants were excluded for failing at least two out of the four attention checks (direct queries) across the survey, 39 participants were excluded due to their short completion times (less than $15 \mathrm{~min}$ ), and five observations for being duplicated. The final sample contained 432 participants with an age average of 38 years $(S D=11$ years), from which $49 \%$ identified themselves as females. 


\section{External Measures}

The selection of measures was based on the goal of validity testing and our procedure of predicting relationships with theoretically related constructs. The selected measures are conceptually related to the dimensions of the GCQ since they provide possible antecedents, consequents of goal characteristics, or goal characteristics themselves.

Relative Autonomy Continuum (Sheldon et al., 2017). The authors used a self-report measure of different motivations (Intrinsic, Identified, Positive Introjection, Negative Introjection, External, and Amotivation) to pursue the chosen goal. Participants rated their agreement with 16 items (e.g., "because I want to prove to myself that I am capable") using a 5point agreement scale.

Necessity from Goal-Striving Reasons (Ehrlich, 2012). As a complementary measure for extrinsic motivation, the Necessity factor from the Goal-Striving Reasons was used, measured by four items focused on the financial motivation necessary for living (e.g., "It helps me to make a living"). Participants used the same 5-point agreement scale.

Commitment (Hollenbeck et al., 1989). To measure commitment, the degree of personal engagement or determination to reach the goal, participants answered a 4-item scale (e.g., "It's unrealistic for me to expect to reach this goal") using the same 5-point agreement scale as before.

Personal Project Analysis (PPA; McGregor \& Little, 1998; Little, 1983). Since the PPA covers several of the goal characteristics in GCQ, it enables us to test the similarity between analogous measures. This instrument contains 37 items measuring several aspects related to goal characteristics (e.g., Importance, Commitment) but also aspects related to goal affect (e.g., "How proud are you to be engaged in each project?") or specific requirements (“How much creativity does each project require of you?"). Factor structures for these instruments were proposed for a 
smaller set of those items. However, we used the whole set of items in this study since they are theoretically independent. Participants answered this measure with a 10-point scale specific for each item (e.g., for the question "How much do you feel you are in control of this project?", participants were instructed to "use 10 if you feel completely in control of the project, and 0 if you feel you have absolutely no control over the project").

GAMMA Scale (Lappi \& Wilkowski, 2020). Approach-Attainment (e.g., "When pursuing this goal, I get excited about the possibility of success"), Approach-Maintenance (e.g., "I am trying to keep my life as ideal as it now") and Avoidance (e.g., "I am trying to improve my poor performance") motivation of general goals were measured using a 13-item scale. Participants rate their agreement with a 7 -point scale $(1=$ completely disagree, $7=$ completely agree).

Affect (12-Point Affect Circumplex; Yik et al., 2011). Using nine selected items from the 12-Point Affect Circumplex, three goal-related affects were measured: Pleasure Activation, Deactivated Pleasure, and Activated Displeasure. For Pleasure Activation, the following items were used: "I felt alive and active", "I felt full of energy", and "Right then, I was brimming with vigor". For Deactivated Pleasure, the items "My mind was soothed and unperturbed", "My mind was pleasantly at ease" and "My mind was at peace with the world" were used. For Activated Displeasure, the items "I felt guilty about something that I had said or done", "I felt ashamed of myself" and "I felt distressed" were used. Participants used the same 5-point agreement scale.

Brief Inventory of Thriving (Su et al., 2014). Individual differences in wellbeing were measured using a 10-item scale related to a wide range of wellbeing constructs, such as selfefficacy (e.g., "I can succeed if I put my mind to it"), self-worth (e.g., "What I do in life is 
valuable and worthwhile"), meaning (e.g., "My life has a clear sense of purpose") and optimism (e.g., "I am optimistic about my future"). Participants used the same 5-point agreement scale.

\section{Procedure}

Participants were recruited via Positly. After the consent form, participants were instructed to think of goals as any desired state that can inform their behavior. As in Study 1, participants were prompted to think and write about a specific goal with a specific time perspective concerning achievement ("today", "this month or "in your life"/“this year"), difficulty ("hard" or "easy") and progress ("Accomplished", "In progress", "Didn't start it yet" or "Gave up"), varying between participants according to randomly assigned conditions. Next, participants were asked to write about their reason for pursuing this goal. After that, participants answered single-item self-report measures of goal stage, difficulty, estimated time to accomplish, when they set this goal, progress, and likelihood of achievement. Then, participants answered the external measures in the following order: 12-PAC, GCQ, Commitment, PPA, RAC, Necessity from Goal Striving Reasons, GAMMA, and BIT scales. The order of items was randomized intra-scale. Finally, participants received a short feedback about their mean scores of the Specificity, Value Congruence, Challenge, and Define Subgoals, and a brief explanation about how this knowledge may help them achieve their goal. This study has been approved by the \{masked for review $\}$.

\section{Data Analysis}

In order to assess the validity of the prompts, differences in self-report measures of goal difficulty, time perspective, and goal progress across conditions were measured. As in Study 1, both a data-driven and a theoretical approach to assess the dimensionality of the GCQ were used. Hypothesized models were modified according to EGA results and compared with alternative 
models. In order to test latent mean differences across conditions, we investigated the scalar invariance of each subscale. In order to access the evidence of validity based on the relation with other variables, the correlation according to the expected relationships of the GCQ factors with the external measures (see Table 17) were tested. A path analysis was conducted to compare the incremental variance explained of commitment and well-being. Due to the ordinal nature of the scale, a diagonally weighted least squares estimator for all models (Li, 2016) was used. Raw data is available at Authors (2021; see references for full link).

\section{Results}

This section first presents the comparison of fit between different factor structures, the loading coefficients, and reliability for each subscale's final version. Subsequently, evidence of measurement invariance and effects of the conditions could be shown. Most importantly, the validity of the GCQ by testing the predicted correlations between the various goal characteristics and external measures of related constructs and internal measures of other goal characteristics could be demonstrated. Finally, it was shown that the GCQ factors explain additional variance in Commitment, and above and beyond, the variance explained by another measure of various goal characteristics, namely the Personal Project Analysis (PPA) method.

\section{Factor Structure}

As shown in Table 9, not all hypothesized structures subscales showed an acceptable fit (e.g., Interestingness Subscale, CFI $=.87, \mathrm{TLI}=.86, \mathrm{RMSEA}=.17, \mathrm{SRMR}=.15$; Bentler, 1990), especially for the subscales where new factors were included. In order to increase the fit, items were excluded based on their low loadings $(<.40)$, inconsistency between EGA solution and theoretical model, and item error covariance. Final factor structures for each subscale have shown a good fit to the data $(\mathrm{CFI} \geq .95, \mathrm{TLI} \geq .94$, RMSEA $\leq .10, \mathrm{SRMR} \leq .08)$. 
Table 9

Fit indices for final structure (modified model) against alternative structures.

\begin{tabular}{lccccccc}
\hline Model & $\chi^{\mathbf{2}}$ & $\mathbf{d f}$ & $\mathbf{C F I}$ & TLI & RMSEA & SRMR & ECVI \\
\hline Content & & & & & & & \\
\hline Null & 31768 & 378 & 0.00 & 0.00 & 0.44 & 0.29 & 74.23 \\
\hline EGA & 2198 & 340 & 0.96 & 0.96 & 0.09 & 0.08 & 3.93 \\
\hline Unifactorial & 13696 & 350 & 0.70 & 0.68 & 0.25 & 0.19 & 23.04 \\
\hline Hypothesized & 2757 & 335 & 0.95 & 0.95 & 0.10 & 0.09 & 4.67 \\
\hline Modified & $\mathbf{1 3 6 6}$ & $\mathbf{2 6 0}$ & $\mathbf{0 . 9 8}$ & $\mathbf{0 . 9 7}$ & $\mathbf{0 . 0 8}$ & $\mathbf{0 . 0 7}$ & $\mathbf{2 . 4 6}$ \\
\hline Hierarchical & 4925 & 269 & 0.89 & 0.88 & 0.16 & 0.14 & 8.27 \\
\hline Framing & & & & & & & \\
\hline Null & 8070 & 231 & 0.00 & 0.00 & 0.28 & 0.22 & 19.13 \\
\hline EGA & 1809 & 203 & 0.85 & 0.82 & 0.12 & 0.10 & 3.71 \\
\hline Unifactorial & 4343 & 209 & 0.59 & 0.55 & 0.19 & 0.14 & 8.30 \\
\hline Hypothesized & 2945 & 206 & 0.71 & 0.68 & 0.16 & 0.14 & 6.15 \\
\hline Modified & $\mathbf{3 4 9}$ & $\mathbf{5 1}$ & $\mathbf{0 . 9 5}$ & $\mathbf{0 . 9 4}$ & $\mathbf{0 . 1 0}$ & $\mathbf{0 . 0 8}$ & $\mathbf{0 . 8 4}$ \\
\hline Hierarchical & & & & Did not converge & & \\
\hline Model & $\chi^{\mathbf{2}}$ & $\mathbf{d f}$ & $\mathbf{C F I}$ & TLI & $\mathbf{R M S E A}$ & SRMR & ECVI \\
\hline Attainability & & & & & & & \\
\hline Null & 56053 & 528 & 0.00 & 0.00 & 0.49 & 0.36 & 13.70 \\
\hline EGA & 4528 & 485 & 0.96 & 0.95 & 0.11 & 0.09 & 6.95 \\
\hline Unifactorial & 14388 & 495 & 0.85 & 0.84 & 0.20 & 0.16 & 2.88 \\
\hline Hypothesized & 5964 & 480 & 0.94 & 0.94 & 0.13 & 0.11 & 9.09 \\
\hline Modified & $\mathbf{2 3 9 5}$ & $\mathbf{3 0 9}$ & $\mathbf{0 . 9 7}$ & $\mathbf{0 . 9 7}$ & $\mathbf{0 . 0 9}$ & $\mathbf{0 . 0 8}$ & $\mathbf{3 . 7 4}$ \\
\hline Hierarchical & 3295 & 318 & 0.95 & 0.95 & 0.11 & 0.09 & 5.09 \\
\hline Resource Availability & & & & & & & \\
\hline Null & 55901 & 561 & 0.00 & 0.00 & 0.48 & 0.34 & 13.30 \\
\hline EGA & 4752 & 517 & 0.95 & 0.95 & 0.11 & 0.10 & 7.91 \\
\hline Unifactorial & 12742 & 527 & 0.86 & 0.85 & 0.18 & 0.14 & 19.25 \\
\hline Hypothesized & 4173 & 506 & 0.96 & 0.96 & 0.10 & 0.09 & 6.71 \\
\hline Modified & $\mathbf{2 6 0 7}$ & $\mathbf{3 5 6}$ & $\mathbf{0 . 9 7}$ & $\mathbf{0 . 9 7}$ & $\mathbf{0 . 0 9}$ & $\mathbf{0 . 0 8}$ & $\mathbf{4 . 2 4}$ \\
\hline Hierarchical & 4236 & 370 & 0.95 & 0.94 & 0.12 & 0.11 & 7.02 \\
\hline Interestingness & & & & & & & \\
\hline Null & 46429 & 528 & 0.00 & 0.00 & 0.45 & 0.33 & 108.30 \\
\hline & & & & & & \\
\hline & & & & & & & \\
\hline
\end{tabular}




\begin{tabular}{lccccccc}
\hline EGA & 6235 & 485 & 0.92 & 0.91 & 0.13 & 0.12 & 9.84 \\
\hline Unifactorial & 13410 & 495 & 0.81 & 0.80 & 0.20 & 0.18 & 21.50 \\
\hline Hypothesized & 9430 & 485 & 0.87 & 0.86 & 0.17 & 0.15 & 15.10 \\
\hline Modified & $\mathbf{1 4 2 4}$ & $\mathbf{1 7 9}$ & $\mathbf{0 . 9 7}$ & $\mathbf{0 . 9 7}$ & $\mathbf{0 . 1 0}$ & $\mathbf{0 . 0 8}$ & $\mathbf{2 . 4 5}$ \\
\hline Hierarchical & 2493 & 184 & 0.94 & 0.94 & 0.13 & 0.11 & 4.07 \\
\hline Usefulness & & & & & & & \\
\hline Null & 50203 & 666 & 0.00 & 0.00 & 0.42 & 0.31 & 117.20 \\
\hline EGA & 5481 & 619 & 0.94 & 0.93 & 0.11 & 0.10 & 9.19 \\
\hline Unifactorial & 13862 & 594 & 0.82 & 0.81 & 0.19 & 0.16 & 22.08 \\
\hline Hypothesized & 11024 & 584 & 0.86 & 0.85 & 0.16 & 0.15 & 17.64 \\
\hline Modified & $\mathbf{1 3 1 9}$ & $\mathbf{1 7 9}$ & $\mathbf{0 . 9 8}$ & $\mathbf{0 . 9 7}$ & $\mathbf{0 . 0 9}$ & $\mathbf{0 . 0 8}$ & $\mathbf{2 . 2 8}$ \\
\hline Hierarchical & 2512 & 184 & 0.94 & 0.94 & 0.14 & 0.12 & 4.19 \\
\hline
\end{tabular}

Note. The null model represents no covariance between observed variables. The EGA models were specified by a network approach to determine the dimensionality. The hypothesized model was defined based on the construction of the items. The modified model was defined based on the modification indices and the theoretically consistent structures indicated by EGA. The hierarchical model tested a hierarchical structure of the modified version with a single hierarchical factor. $\chi^{2}=$ Chi-Square with Satorra-Bentler correction; $\mathrm{df}=$ degrees of freedom; $\mathrm{CFI}=$ Comparative Fit Index; TLI $=$ Tucker Lewis index RMSEA $=$ Root Mean Square Error of Approximation; SRMSR $=($ Standardized $)$ Root Mean Square Residual; ECVI $=$ Expected Cross Validation Index.

Tables 10-15 shows the loading coefficients and reliability for the factors of the modified version of each subscale. All Cronbach's $\alpha$ coefficients were higher than .70, except for Outcome Focus. No items showed loadings lower than .40 , and most of the factors show loadings higher than .60. Interfactor correlations showed again great variability of relationships between the goal characteristics $\left(M_{|r|}=.33, \mathrm{SD}_{|r|}=.24\right)$. Some interfactor correlations ( 7 out of 496$)$ were still very 
high $(|r| \geq .90)$. Interfactor correlation matrix and additional reliability measures are reported in the Supplementary Material (Section 6 and 7). In general, factors showed good reliability and medium to high loadings.

Table 10

Standardized loading coefficients ( $\lambda$ ) and Cronbach's $\alpha$ reliability for the Structural Subscale.

\begin{tabular}{|c|c|c|c|c|c|c|c|c|c|c|c|}
\hline \multicolumn{2}{|c|}{$\begin{array}{c}\text { Content } \\
\text { Specificity } \\
(\alpha=.77)\end{array}$} & \multicolumn{2}{|c|}{$\begin{array}{c}\text { Time } \\
\text { Specificity } \\
(\alpha=.87) \\
\end{array}$} & \multicolumn{2}{|c|}{$\begin{array}{c}\text { Hierarchy - } \\
\text { High Level } \\
(\alpha=.78) \\
\end{array}$} & \multicolumn{2}{|c|}{$\begin{array}{c}\text { Hierarchy - } \\
\text { Low Level } \\
(\alpha=.90)\end{array}$} & \multicolumn{2}{|c|}{$\begin{array}{c}\text { Network } \\
\text { Congruence } \\
(\alpha=.80)\end{array}$} & \multicolumn{2}{|c|}{$\begin{array}{l}\text { Measurability } \\
\quad(\alpha=.87)\end{array}$} \\
\hline Item & $\lambda$ & Item & $\lambda$ & Item & $\lambda$ & Item & $\lambda$ & Item & $\lambda$ & Item & $\lambda$ \\
\hline 1 & .609 & 7 & .757 & 11 & .843 & 16 & .876 & 20 & .659 & 24 & .787 \\
\hline 2 & 609 & 8 & .847 & 12 & .565 & 17 & .853 & 21 & .802 & 25 & .793 \\
\hline 3 & .618 & 9 & .849 & 13 & .544 & 18 & .843 & 22 & .821 & 26 & .838 \\
\hline 4 & .665 & 10 & .739 & 14 & .867 & 19 & .754 & & & 27 & .725 \\
\hline 6 & .690 & & & & & & & & & 28 & .687 \\
\hline
\end{tabular}

Note. For a complete description of the items and other reliability measures, McDonald's Omega and Average Variance Extracted, see Supplementary Material, Section 6.

Table 11

Standardized loading coefficients $(\lambda)$ and Cronbach's a reliability for Framing Subscale.

\begin{tabular}{|c|c|c|c|c|c|}
\hline \multicolumn{2}{|c|}{$\begin{array}{c}\text { Approach-Avoidanc } \\
\text { Framing } \\
(\alpha=.84) \\
\end{array}$} & \multicolumn{2}{|c|}{$\begin{array}{l}\text { Process Focus } \\
\quad(\alpha=.76)\end{array}$} & \multicolumn{2}{|c|}{$\begin{array}{l}\text { Outcome Focus } \\
\quad(\alpha=.63)\end{array}$} \\
\hline Item & $\lambda$ & Item & $\lambda$ & Item & $\lambda$ \\
\hline 29 & .755 & 44 & .514 & 46 & .480 \\
\hline 30 & .642 & 45 & .913 & 48 & .554 \\
\hline 31 & .721 & 50 & .744 & 49 & .816 \\
\hline 32 & .642 & & & & \\
\hline 33 & .670 & & & & \\
\hline 35 & .745 & & & & \\
\hline
\end{tabular}


Table 12

Standardized loading coefficients ( $\lambda$ ) and Cronbach's a reliability for Attainability Subscale.

\begin{tabular}{|c|c|c|c|c|c|c|c|c|c|c|c|}
\hline \multicolumn{2}{|c|}{$\begin{array}{c}\text { Immediately } \\
\text { Actionable } \\
(\alpha=.80)\end{array}$} & \multicolumn{2}{|c|}{$\begin{array}{c}\text { Required } \\
\text { Effort } \\
(\alpha=.76) \\
\end{array}$} & \multicolumn{2}{|c|}{$\begin{array}{l}\text { Plannability } \\
(\alpha=.89)\end{array}$} & \multicolumn{2}{|c|}{$\begin{array}{l}\text { Controllability } \\
\quad(\alpha=.89) \\
\end{array}$} & \multicolumn{2}{|c|}{$\begin{array}{c}\text { Challenge } \\
(\alpha=.79)\end{array}$} & \multicolumn{2}{|c|}{$\begin{array}{l}\text { Defined Subgoals } \\
\quad(\alpha=.77) \\
\end{array}$} \\
\hline Item & $\lambda$ & Item & $\lambda$ & Item & $\lambda$ & Item & $\lambda$ & Item & $\lambda$ & Item & $\lambda$ \\
\hline 51 & .645 & 57 & .465 & 62 & .827 & 68 & .692 & 75 & .868 & 79 & .849 \\
\hline 52 & .667 & 58 & .817 & 63 & .772 & 69 & .665 & 76 & .663 & 80 & .827 \\
\hline 53 & .754 & 59 & .846 & 64 & .794 & 70 & .763 & 77 & .733 & 81 & .470 \\
\hline 54 & .794 & & & 65 & .681 & 72 & .791 & 74 & .522 & & \\
\hline 55 & .627 & & & 66 & .862 & 73 & .832 & & & & \\
\hline & & & & & & 67 & .698 & & & & \\
\hline & & & & & & 71 & .826 & & & & \\
\hline
\end{tabular}

Table 13

Standardized loading coefficients ( $\lambda$ ) and Cronbach's a reliability for Resource Availability

Subscale.

\begin{tabular}{|c|c|c|c|c|c|c|c|c|c|c|c|c|c|}
\hline \multicolumn{2}{|c|}{$\begin{array}{c}\text { Social } \\
\text { Support } \\
(\alpha=.76) \\
\end{array}$} & \multicolumn{2}{|c|}{$\begin{array}{c}\text { Informational } \\
\text { Support } \\
(\alpha=.86)\end{array}$} & \multicolumn{2}{|c|}{$\begin{array}{c}\text { Instrumental } \\
\text { Support } \\
(\alpha=.88) \\
\end{array}$} & \multicolumn{2}{|c|}{$\begin{array}{c}\text { Financial } \\
\text { Affordance } \\
(\alpha=.87) \\
\end{array}$} & \multicolumn{2}{|c|}{$\begin{array}{l}\text { Visibility } \\
(\alpha=.71)\end{array}$} & \multicolumn{2}{|c|}{$\begin{array}{c}\text { Time } \\
\text { Availability } \\
(\alpha=.86)\end{array}$} & \multicolumn{2}{|c|}{$\begin{array}{c}\text { Competence } \\
\text { Adequacy } \\
(\alpha=.89)\end{array}$} \\
\hline Item & $\lambda$ & Item & $\lambda$ & Item & $\lambda$ & Item & $\lambda$ & Item & $\lambda$ & Item & $\lambda$ & Item & $\lambda$ \\
\hline 84 & .585 & 88 & .768 & 95 & .804 & 99 & .644 & 104 & .618 & 109 & .754 & 113 & .833 \\
\hline 85 & .626 & 89 & .783 & 96 & .851 & 100 & .86 & 105 & .603 & 110 & .805 & 114 & .835 \\
\hline 86 & .74 & 90 & .851 & 97 & .812 & 101 & .787 & 106 & 697 & 111 & .751 & 115 & .798 \\
\hline \multirow[t]{2}{*}{87} & .747. & 91 & .543 & 98 & .810 & 102 & .854 & 107 & .613 & 112 & .820 & 116 & .847 \\
\hline & & 92 & .808 & & & & & & & & & & \\
\hline
\end{tabular}


Table 14

Standardized loading coefficients ( $\lambda$ ) and Cronbach's a reliability for Interestingness Subscale.

\begin{tabular}{cccccccccc}
\hline $\begin{array}{c}\text { Self- } \\
\text { Congruence } \\
(\alpha=.74)\end{array}$ & \multicolumn{2}{c}{$\begin{array}{c}\text { Value } \\
\text { Congruence } \\
(\alpha=.86)\end{array}$} & \multicolumn{2}{c}{$\begin{array}{c}\text { Importance } \\
(\alpha=.82)\end{array}$} & \multicolumn{2}{c}{$\begin{array}{c}\text { Awareness } \\
(\alpha=.81)\end{array}$} & \multicolumn{2}{c}{$\begin{array}{c}\text { Vitality } \\
(\alpha=.90)\end{array}$} \\
\hline Item & $\lambda$ & Item & $\lambda$ & Item & $\lambda$ & Item & $\lambda$ & Item & $\lambda$ \\
\hline 118 & .697 & 122 & .731 & 135 & .612 & 140 & .511 & 145 & .895 \\
\hline 121 & .751 & 128 & .714 & 136 & .766 & 143 & .918 & 146 & .822 \\
\hline 124 & .784 & 129 & .759 & 137 & .775 & 142 & .910 & 147 & .869 \\
\hline 126 & .533 & 130 & .745 & 138 & .595 & 144 & .594 & & \\
\hline & & 131 & .745 & 139 & .701 & & & & \\
\hline
\end{tabular}

Table 15

Standardized loading coefficients ( $\lambda$ ) and Cronbach's a reliability for Usefulness Subscale.

\begin{tabular}{cccccccccc}
\hline $\begin{array}{c}\text { Long-Term } \\
\text { Utility } \\
(\alpha=.88)\end{array}$ & $\begin{array}{c}\text { Short-Term } \\
\text { Utility } \\
(\alpha=.73)\end{array}$ & \multicolumn{2}{c}{$\begin{array}{c}\text { Relative Utility } \\
(\alpha=.85)\end{array}$} & $\begin{array}{c}\text { Self-Improvement } \\
\text { Utility } \\
(\alpha=.86)\end{array}$ & \multicolumn{2}{c}{$\begin{array}{c}\text { Negative Utility } \\
(\alpha=.91)\end{array}$} \\
\hline Item & $\lambda$ & Item & $\lambda$ & Item & $\lambda$ & Item & $\lambda$ & Item & $\lambda$ \\
\hline 151 & .793 & 161 & .680 & 179 & .808 & 184 & .841 & 158 & .845 \\
\hline 153 & .848 & 164 & .593 & 180 & .658 & 185 & .613 & 159 & .893 \\
\hline 154 & .714 & 165 & .827 & 182 & .790 & 186 & .897 & 167 & .748 \\
\hline 157 & .856 & 166 & .551 & 183 & .825 & 187 & .821 & 168 & .838 \\
\hline & & & & & & & 169 & .733 \\
\hline
\end{tabular}

\section{Effects of Conditions}

Before comparing factor scores between conditions, configural, metric, and scalar invariance were tested across different time perspectives, difficulty, and progress independently with the same method described in Study 1. For all subscales, fit indices did not decrease above thresholds of $\Delta$ CFI $>-.01, \Delta$ RMSEA $>0.15$ and $\Delta$ SRMR $>0.15$ (Chen, 2007; Cheung \& 
Rensvold, 2002), suggesting scalar invariance across time perspectives, difficulty and progress for all subscales. For detailed fit indices, see Supplementary Material.

Since the conditions elicit goals with a specific time perspective, difficulty, and progress, we expected to observe variability between their characteristics. As shown in Table 16, there are statistically significant direct effects of the conditions, indicating that goal characteristics vary across different progress levels, time perspectives, and difficulty levels. No interaction effect was significant, indicating general independence of the conditions. Univariate effects were not the primary goal of this paper. Post-hoc analyses for the effect of the conditions on individual GCQ factors are reported in the Supplementary Material.

Table 16

Multivariate statistics for direct and interaction effects of the conditions on GCQ factor scores.

\begin{tabular}{|c|c|c|c|c|c|c|c|}
\hline & & Pillai's & & & & & \\
\hline Effect & $d f$ & Trace & $F($ df1, & df2) & $F$ & $p$ & $\eta p^{2}$ \\
\hline Progress & 3 & .514 & 96 & 1137 & 2.450 & $<.0001$ & .170 \\
\hline Time Perspective & 2 & .452 & 64 & 756 & 3.450 & $<.0001$ & .220 \\
\hline Difficulty & 1 & .261 & 32 & 377 & 4.160 & $<.0001$ & .262 \\
\hline Progress $\times$ Time Perspective & 6 & .521 & 192 & 2292 & 1.130 & .108 & .087 \\
\hline Progress $\times$ Difficulty & 3 & .247 & 96 & 1137 & 1.060 & .326 & .083 \\
\hline Time Perspective $\times$ Difficulty & 2 & .173 & 64 & 756 & 1.120 & .256 & .086 \\
\hline $\begin{array}{l}\text { Progress } \times \text { Time Perspective } \times \\
\text { Difficulty }\end{array}$ & 6 & .491 & 192 & 2292 & 1.060 & .269 & .082 \\
\hline Residuals & 408 & & & & & & \\
\hline
\end{tabular}

\section{Relations with other Goal-Related Measures}

Table 17 shows the observed correlations between the external measures and expected association with the GCQ. The authors derived a set of hypotheses about the direction of 
correlations between GCQ factors (positive or negative), which are expressed in the "expected relationships" column in the table. Most of the expected relationships, 82 out of 96 hypotheses, were statistically significant.

Table 17

Expected direction of relationship (positive correlation (+) or negative correlation (-)) between GCQ factor scores and external measures, Pearson correlation ( $r$ ), and significance level ( $p$ ).

The last column shows if the expected relationships were confirmed $(\checkmark)$ or not $(\neg)$.

\begin{tabular}{|c|c|c|c|c|c|}
\hline External Measure & GCQ & $\begin{array}{c}\text { Expected } \\
\text { Relationship }\end{array}$ & $\mathbf{r}$ & $\mathbf{p}$ & $\begin{array}{l}\text { Confirmed } \\
\text { Prediction }\end{array}$ \\
\hline \multicolumn{6}{|c|}{ Personal Project Analysis } \\
\hline Absorption & Vitality & + & .44 & $<.00001$ & $\sqrt{ }$ \\
\hline Challenge & Challenge & + & .72 & $<.00001$ & $\sqrt{ }$ \\
\hline Competence & $\begin{array}{c}\text { Competence } \\
\text { Adequacy } \\
\end{array}$ & + & .61 & $<.00001$ & $\checkmark$ \\
\hline Control & Controllability & + & .57 & $<.00001$ & $\sqrt{ }$ \\
\hline Difficulty & Estimated Effort & + & .65 & $<.00001$ & $\checkmark$ \\
\hline \multirow{2}{*}{ Enjoyment } & Vitality & + & .71 & $<.00001$ & $\checkmark$ \\
\hline & Self-Congruence & + & .66 & $<.00001$ & $\checkmark$ \\
\hline Fun & Vitality & + & .63 & $<.00001$ & $\checkmark$ \\
\hline \multirow[b]{2}{*}{ Future Self } & Long-Term Utility & + & .68 & $<.00001$ & $\checkmark$ \\
\hline & $\begin{array}{c}\text { Hierarchy - High } \\
\text { Level } \\
\end{array}$ & + & .70 & $<.00001$ & $\checkmark$ \\
\hline Importance & Importance & + & .57 & $<.00001$ & $\checkmark$ \\
\hline Meaningfulness & Value-Congruence & + & .61 & $<.00001$ & $\checkmark$ \\
\hline Net Impact & Network Congruence & + & .51 & $<.00001$ & $\checkmark$ \\
\hline Net Social Support & Social Support & + & .47 & $<.00001$ & $\checkmark$ \\
\hline Pleasure & Vitality & + & .60 & $<.00001$ & $\checkmark$ \\
\hline Purpose & Value Congruence & + & .41 & $<.00001$ & $\checkmark$ \\
\hline Self-Benefit & $\begin{array}{c}\text { Self-Improvement } \\
\text { Utility }\end{array}$ & + & .32 & $<.00001$ & $\checkmark$ \\
\hline Self-Identity & Self-Congruence & + & .48 & $<.00001$ & $\checkmark$ \\
\hline Self-Worth & Value Congruence & + & .50 & $<.00001$ & $\checkmark$ \\
\hline
\end{tabular}




\begin{tabular}{lccccc}
\hline Significance & Value Congruence & + & .52 & $<.00001$ & $\checkmark$ \\
\hline Stress & Effort & + & .66 & $<.00001$ & $\checkmark$ \\
\hline Time Pressure & Time Availability & + & .60 & $<.00001$ & $\checkmark$ \\
\hline Trust & Social Support & + & .27 & $<.00001$ & $\checkmark$ \\
\hline Value Congruency & Value Congruence & + & .54 & $<.00001$ & $\checkmark$ \\
\hline Visibility & Visibility & + & .56 & $<.00001$ & $\checkmark$ \\
\hline Responsibility & Controllability & + & .43 & $<.00001$ & $\checkmark$ \\
\hline
\end{tabular}

\section{Relative Autonomy Continuum}

\begin{tabular}{|c|c|c|c|c|c|}
\hline \multirow{6}{*}{ Amotivation } & Awareness & - & -.61 & $<.00001$ & $\checkmark$ \\
\hline & Long-Term Utility & - & -.31 & $<.00001$ & $\checkmark$ \\
\hline & Short-Term Utility & - & -.62 & $<.00001$ & $\checkmark$ \\
\hline & Relative Utility & - & -.16 & .0006 & $\neg$ \\
\hline & $\begin{array}{c}\text { Self-Improvement } \\
\text { Utility } \\
\end{array}$ & - & -.16 & .0007 & ᄀ \\
\hline & Negative Utility & - & -.70 & $<.00001$ & $\checkmark$ \\
\hline \multirow{4}{*}{ External } & Self-Congruence & - & -.28 & $<.00001$ & $\checkmark$ \\
\hline & Value Congruence & - & -.31 & $<.00001$ & $\checkmark$ \\
\hline & Importance & + & -.41 & $<.00001$ & $\checkmark$ \\
\hline & Vitality & - & -.32 & $<.00001$ & $\checkmark$ \\
\hline Negative Introjectior & Approach-Avoidance & - & -.43 & $<.00001$ & $\checkmark$ \\
\hline \multirow{3}{*}{ Positive Introjection } & Approach-Avoidance & + & .04 & .44 & $\neg$ \\
\hline & Challenge & + & .40 & $<.00001$ & $\checkmark$ \\
\hline & $\begin{array}{c}\text { Self-Improvement } \\
\text { Utility }\end{array}$ & + & .62 & $<.00001$ & $\checkmark$ \\
\hline \multirow{4}{*}{ Identified } & Value Congruence & + & .75 & $<.00001$ & $\checkmark$ \\
\hline & Importance & + & .69 & $<.00001$ & $\checkmark$ \\
\hline & Awareness & + & .36 & $<.00001$ & $\checkmark$ \\
\hline & Long-Term Utility & + & .68 & $<.00001$ & $\checkmark$ \\
\hline \multirow{4}{*}{ Intrinsic } & Vitality & + & .72 & $<.00001$ & $\checkmark$ \\
\hline & Importance & + & .32 & $<.00001$ & $\checkmark$ \\
\hline & Self-Congruence & + & .72 & $<.00001$ & $\checkmark$ \\
\hline & Value Congruence & + & .53 & $<.00001$ & $\checkmark$ \\
\hline \multirow{3}{*}{ Necessity } & Self-Congruence & - & .20 & .00004 & $\checkmark$ \\
\hline & Value Congruence & - & .14 & .004 & $\neg$ \\
\hline & Importance & - & .05 & .26 & $\neg$ \\
\hline
\end{tabular}

\section{Commitment}




\begin{tabular}{|c|c|c|c|c|c|}
\hline \multirow{21}{*}{ Commitment } & Self-Congruence & + & -.36 & $<.00001$ & $\checkmark$ \\
\hline & Value-Congruence & + & -.50 & $<.00001$ & $\sqrt{ }$ \\
\hline & Importance & + & -.70 & $<.00001$ & $\checkmark$ \\
\hline & Awareness & + & -.58 & $<.00001$ & $\checkmark$ \\
\hline & Vitality & + & -.34 & $<.00001$ & $\checkmark$ \\
\hline & Long-Term Utility & + & -.40 & $<.00001$ & $\sqrt{ }$ \\
\hline & Short-Term Utility & + & -.61 & $<.00001$ & $\checkmark$ \\
\hline & Relative Utility & + & -.27 & $<.00001$ & $\sqrt{ }$ \\
\hline & $\begin{array}{c}\text { Self-Improvement } \\
\text { Utility }\end{array}$ & + & -.26 & $<.00001$ & $\checkmark$ \\
\hline & Negative Utility & + & -.64 & $<.00001$ & $\checkmark$ \\
\hline & $\begin{array}{c}\text { Immediately } \\
\text { Actionable }\end{array}$ & + & -.65 & $<.00001$ & $\checkmark$ \\
\hline & Plannability & + & -.65 & $<.00001$ & $\checkmark$ \\
\hline & Controllability & + & -.67 & $<.00001$ & $\checkmark$ \\
\hline & Challenge & + & .20 & .00003 & $\bar{\checkmark}$ \\
\hline & Defined Subgoals & + & -.56 & $<.00001$ & $\sqrt{ }$ \\
\hline & Content Specificity & + & -.55 & $<.00001$ & $\bar{\checkmark}$ \\
\hline & Time Specificity & + & -.33 & $<.00001$ & $\sqrt{ }$ \\
\hline & $\begin{array}{c}\text { Competence } \\
\text { Adequacy } \\
\end{array}$ & + & -.66 & $<.00001$ & $\checkmark$ \\
\hline & Network Congruence & + & -.32 & $<.00001$ & $\sqrt{ }$ \\
\hline & Social Support & + & -.11 & .03 & $\neg$ \\
\hline & Visibility & + & -.37 & $<.00001$ & $\checkmark$ \\
\hline \multicolumn{6}{|c|}{ GAMMA Motivation Scale } \\
\hline \multirow{2}{*}{$\begin{array}{l}\text { Approach- } \\
\text { Attainment }\end{array}$} & $\begin{array}{c}\text { Approach-Avoidance } \\
\text { Framing } \\
\end{array}$ & + & .13 & .007 & $\neg$ \\
\hline & Process & + & .13 & .007 & $\neg$ \\
\hline \multirow{2}{*}{$\begin{array}{l}\text { Approach- } \\
\text { Maintenance }\end{array}$} & Process & + & .18 & .00014 & $\sqrt{ }$ \\
\hline & Outcome & - & -.24 & $<.00001$ & $\bar{\checkmark}$ \\
\hline Avoidance & Approach-Avoidance & - & -.51 & $<.00001$ & $\bar{\checkmark}$ \\
\hline \multicolumn{6}{|c|}{ Brief Inventory of Thriving } \\
\hline \multirow{4}{*}{ Thriving } & $\begin{array}{c}\text { Hierarchy - High } \\
\text { Level } \\
\end{array}$ & + & .29 & $<.00001$ & $\checkmark$ \\
\hline & $\begin{array}{c}\text { Hierarchy - Low } \\
\text { Level }\end{array}$ & + & .25 & $<.00001$ & $\checkmark$ \\
\hline & Self-Congruence & + & .48 & $<.00001$ & $\checkmark$ \\
\hline & Value Congruence & + & .40 & $<.00001$ & $\checkmark$ \\
\hline
\end{tabular}




\begin{tabular}{|c|c|c|c|c|c|}
\hline & Long-Term Utility & + & .38 & $<.00001$ & $\checkmark$ \\
\hline & Short-Term Utility & + & .28 & $<.00001$ & $\checkmark$ \\
\hline \multicolumn{6}{|l|}{ Affect } \\
\hline \multirow{4}{*}{ Pleasant Activation } & Vitality & + & .71 & $<.00001$ & $\checkmark$ \\
\hline & Approach Avoidance & + & .07 & .13 & $\neg$ \\
\hline & Financial Affordance & + & .06 & .24 & $\neg$ \\
\hline & $\begin{array}{c}\text { Competence } \\
\text { Adequacy }\end{array}$ & + & .10 & .03 & $\neg$ \\
\hline \multirow{8}{*}{$\begin{array}{l}\text { Deactivated } \\
\text { Pleasure }\end{array}$} & Plannability & + & .25 & $<.00001$ & $\checkmark$ \\
\hline & Controllability & + & .21 & .00001 & $\checkmark$ \\
\hline & Social Support & + & .19 & .00008 & $\checkmark$ \\
\hline & Informational Support & + & .23 & $<.00001$ & $\checkmark$ \\
\hline & Instrumental Support & + & .14 & .003 & $\neg$ \\
\hline & Financial Affordance & + & .15 & .002 & $\neg$ \\
\hline & Time Availability & + & .34 & $<.00001$ & $\sqrt{ }$ \\
\hline & $\begin{array}{l}\text { Competence } \\
\text { Adequacy }\end{array}$ & + & .23 & $<.00001$ & $\checkmark$ \\
\hline \multirow{6}{*}{$\begin{array}{l}\text { Activated } \\
\text { Displeasure }\end{array}$} & Approach-Avoidance & - & -.43 & $<.00001$ & $\checkmark$ \\
\hline & Self-Congruence & - & -.28 & $<.00001$ & $\bar{v}$ \\
\hline & Value Congruence & - & -.18 & .00012 & $\sqrt{ }$ \\
\hline & Awareness & - & -.07 & .14 & $\neg$ \\
\hline & $\begin{array}{l}\text { Competence } \\
\text { Adequacy }\end{array}$ & - & -.39 & $<.00001$ & $\checkmark$ \\
\hline & Informational Support & - & -.38 & $<.00001$ & $\checkmark$ \\
\hline
\end{tabular}

Note. $\checkmark$ indicates confirmed predictions, while $\neg$ indicates non-confirmed ones (non-significant at a correct alpha level of .00054 or significant in the unexpected direction).

\section{Commitment and Thriving Variance Explained}

To assess the incremental variance explained by the GCQ to previous measures, the variance of Commitment and Thriving that is explained by the PPA and the GCQ, were compared using a path analysis. For GCQ factors, scores were calculated based on the CFA using the Empirical Bayes Modal method (Morris, 1983). It was found that the PPA alone explains $50.2 \%$ of Commitment and $37.7 \%$ of Thriving, while the GCQ alone explains $74.7 \%$ variance of 
Commitment and $47.6 \%$ variance of Thriving. Together both instruments explain $78.7 \%$ variance of Commitment and $54.6 \%$ of Thriving. Therefore, the GCQ increases the ability to explain both commitment and well-being when compared to the most comprehensive measure previously used in the literature.

\section{Discussion}

The main goal of this study was to provide evidence for convergent validity by testing a set of hypotheses about correlations of GCQ dimensions with dimensions of external measures. From the 96 hypotheses, 82 (85\%) were confirmed. A great part of unconfirmed hypotheses $(42 \%)$ was related to affective constructs, which points at the complex relationships between goal-related constructs and affect that might have not been captured in this study. In sum, Study 2 demonstrates solid evidence for convergent validity, showing that the GCQ factors align with established motivational constructs and commitment.

\section{General Discussion}

The Goal Characteristics Questionnaire was developed to integrate dimensions from established goal characteristics measures and goal-relevant characteristics that have not systematically been measured before. Based on previous research, the systematic development procedure led to a final version of the measure with six subscales measuring 32 factors with 187 items, which is now ready to be used by the scientific community of motivation researchers.

We have demonstrated that the Goal Characteristics Questionnaire is a valid measure of the constructs it is supposed to measure according to the following criteria of the APA Standards for Educational and Psychological Testing (AERA, APA, NCME, 2014): 
1. Evidence of validity based on test content was established through the initial scale construction. The item generation process built upon previous findings and wordings from existing measures were adapted. The semantics were constructed upon relevant constructs and operationalizations of former research. In addition, theoretically ambiguous items were excluded through an item-sort task. In the following iterations of scale refinement, the items were reformulated, new items added, and older items replaced by experts to adequately represent the constructs to be measured. This process converged into an item set that covers a wide range of essential goal characteristics space.

2. Evidence of validity based on response processes was established through an elicitation procedure, which explicitly evoked goals with different characteristics in distinct progress, time perspective, and difficult conditions. For instance, goals elicited by a prompt asking for a difficult goal resulted in higher scores for the challenge characteristic.

3. Evidence of validity based on the internal structure was demonstrated in Study 1 and Study 2. The item-latent-variable correlation and the dimensionality were demonstrated by comparing different models in confirmatory factor analyses, including data-driven models. Factors also showed adequate reliability. Moreover, the final version of the GCQ was invariant across different conditions. Taken together, these results suggest the GCQ is a robust measure for different goals regardless of how much progress the person already invested in, the time window associated with this goal, and its difficulty. 
4. Evidence of validity based on relations to other variables was demonstrated in Study 2, based on correlations with external measures. The findings show that the latent variables measured by the GCQ highly correlate with latent variables measured by a broad range of other well-established measures used in motivation and goal-setting research.

The presented evidence of validity is a solid foundation for the practical application of the GCQ. Future research, especially longitudinal studies, should expand on this foundation and improve the GCQ towards predicting sustained commitment and actual performance.

\section{Limitations}

Some readers may have missed some characteristics, such as intrinsic and extrinsic goals, mastery and performance goals, or proximal and distal goals. The aforementioned characteristics were excluded because the intrinsic-extrinsic continuum is a complex multidimensional construct in itself that is, in our view, best considered part of a motivational process. The mastery-performance dimension is specific to educational contexts and is related to the reference frame for evaluating goal success. While mastery goals are about achieving a skill or mastering a task, performance goals are about performing well compared to others. This dichotomy has been extended to a trichotomy of reference frames: task (related to a specific external challenge), self (related to one's own past performance), or the performance of others. As the masteryperformance dichotomy has been outdated by the $3 \times 2$ model of achievement goals (see Murayama \& Elliot 2019), a trichotomy on a nominal scale cannot be captured as a single characteristic on an ordinal scale level. It remains an open question how to integrate this concept into the GCQ. A separation into more than one dimension is a possibility that needs to be empirically investigated. 
The continuum between proximal and distal goals frequently used in the literature (e.g., Locke \& Latham, 2002) is not covered as a goal characteristic because the operationalization is context-dependent. Passing an exam may be a proximal goal in the context of career planning but a distal goal in the context of semester planning. Researchers can simply do a proper operationalization by asking for specific temporal horizons.

It is important to note that, due to the nature of self-report measures, the operationalization of the measures is intended to reflect the subjective perception of a personal goal. The GCQ does not measure objective goal characteristics, so the same goal may be yield different goal characteristics by different persons and the characteristics assigned by the same person may develop over time.

\section{Future Directions}

With the GCQ, researchers can use context independent goal-related measures. For instance, the effects of goal-setting interventions can be systematically compared to each other, and a broad range of goal characteristics can be assessed with only one coherent framework. The use of a standard measure makes it easier to directly compare results from different studies. The GCQ, with its broad scope, has the potential to simplify the collection of standardized data about goals in a time when making study data publicly available is becoming part of good scientific practice. These examples are just a subset of the new methodological possibilities the GCQ provides for the scientific community.

The predictive power of goal characteristics over goal setting outcomes, such as goal progress, achievement, and well-being, can be investigated in longitudinal studies. The predictive power of specific characteristics might depend on the context or person's trait. As a 
consequence, interventions should also investigate individual differences in order to personalize and optimize their effects.

\section{Prediction of Other Goal-Related Constructs}

The full potential of the GCQ for motivation and goal setting science remains to be unfolded: some of the goal characteristics that are not explicitly part of the current GCQ might be concluded based on a combination of covered characteristics. Correlations between goal characteristics and the probability of goal achievement, for instance, are a promising and worthwhile field of investigation. If the GCQ could be used to make good predictions about the probability of goal achievement, this may help to simplify study designs and reduce temporal effort of goal setting studies substantially. As the field of goal setting research progresses rapidly, new relevant goal characteristics may be identified and integrated or built upon the contained characteristics. Its multidimensional structure makes the GCQ a solid foundation for this kind of extension.

\section{Conclusion}

This paper has introduced a new and more comprehensive measure for goal characteristics, which integrates objective, valid, and reliable measures of 32 constructs of great relevance for motivation research into a single framework and overcomes many methodological and conceptual limitations of previous operationalizations. Two studies have demonstrated the evidences of validity of the GCQ based on the Standards for Educational and Psychological Testing (AERA, APA, NCME, 2014). Its application has the potential to encourage motivation researchers to systematize and evaluate goal characteristics measures, elucidate previously overlooked effects of known interventions and to investigate the causes and consequences of goal characteristics across different contexts. 


\section{References}

Aarts, H., Custers, R., \& Veltkamp, M. (2008). Goal priming and the affective-motivational route to nonconscious goal pursuit. Social Cognition, 26(5), 555577.https://doi.org/10.1521/soco.2008.26.5.555

Aarts, H., Gollwitzer, P. M., \& Hassin, R. R. (2004). Goal contagion: Perceiving is for pursuing. Journal of Personality and Social Psychology, 87(1), 23-37. https://doi.org/10.1037/0022-3514.87.1.23

American Educational Research Association, American Psychological Association, National Council on Measurement in Education (2014). Standards for Educational and Psychological Testing. Washington, D.C.: American Educational Research Association.

Anderson, J. C., \& Gerbing, D. W. (1991). Predicting the performance of measures in a confirmatory factor analysis with a pretest assessment of their substantive validities. Journal of Applied Psychology, 76(5), 732-74. https://doi.org/10.1037/00219010.76 .5 .732

Authors (2021). Goal Characteristics Questionnaire. Retrieved from https://osf.io/3gxk5/?view_only=1ff0e62127c64b82862a0fe7d73c4faf

Ballard, T., Yeo, G., Loft, S., Vancouver, J. B., \& Neal, A. (2016). An integrative formal model of motivation and decision making: The MGPM*. Journal of Applied Psychology, 101(9), 1240-1265. http://dx.doi.org/10.1037/apl0000121

Bandura, A. (1977). Self-efficacy: Toward a unifying theory of behavioral change. Psychological Review, 84(2), 191-215. https://doi.org/10.1037/0033-295X.84.2.191

Bandura, A. (1982). Self-efficacy mechanism in human agency. American Psychologist, 37(2), 122-147. https://doi.org/10.1037/0003-066X.37.2.122 
Bandura, A. (1997). Self-efficacy: The exercise of control. New York: W. H. Freeman.

Bargh, J. A., Gollwitzer, P. M., Lee-Chai, A., Barndollar, K., \& Trötschel, R. (2001). The automated will: Nonconscious activation and pursuit of behavioral goals. Journal of Personality and Social Psychology, 81(6), 1014-1027. https://doi.org/10.1037/00223514.81.6.1014

Bauer, J. J., \& McAdams, D. P. (2010). Eudaimonic Growth: Narrative Growth Goals Predict Increases in Ego Development and Subjective Well-Being 3 Years Later. Developmental Psychology, 46(4), 761-772. https://doi.org/1.1037/a0019654

Bentler, P. M. (1990). Comparative fit indexes in structural models. Psychological Bulletin, 107(2), 238-246. https://doi.org/1.1037/0033-2909.107.2.238

Bjork, R. A., Dunlosky, J., \& Kornell, N. (2013). Self-Regulated Learning: Beliefs, Techniques, and Illusions. Annual Review of Psychology, 64(1), 417-444. https://doi.org/1.1146/annurev-psych-113011-143823

Boldero, J., \& Francis, J. (2002). Goals, standards, and the self: Reference values serving different functions. Personality and Social Psychology Review, 6(3), 232-241. https://doi.org/10.1207/S15327957PSPR0603_7

Bouffard, T., Boisvert, J., Vezeau, C., \& Larouche, C. (1995). The impact of goal orientation on self-regulation and performance among college students. British Journal of Educational Psychology, 65(3), 317-329. https://doi.org/1.1111/j.2044-8279.1995.tb01152.x

Carver, C. S., \& Scheier, M. F. (2001). On the Self-Regulation of Behavior. Cambridge University Press. 
Chen, F. F. (2007). Sensitivity of goodness of fit indexes to lack of measurement invariance. Structural Equation Modeling: A Multidisciplinary Journal, 14(3), 464-504. https://doi.org/1.1080/10705510701301834

Cheung, G. W., \& Rensvold, R. B. (2002). Evaluating goodness-of-fit indexes for testing measurement invariance. Structural Equation Modeling: A Multidisciplinary Journal, 9(2), 233-255. https://doi.org/1.1207/S15328007SEM0902_5

Chidester, T. R., \& Grigsby, W. C. (1984). A meta-analysis of the goal setting-performance literature. Academy of Management Proceedings, 1984(1), 202-206. https://doi.org/1.5465/ambpp.1984.4978779

Cooper, R. P., \& Shallice, T. (2006). Hierarchical schemas and goals in the control of sequential behavior. Psychological Review, 113(4), 887-916. https://doi.org/1.1037/0033295X.113.4.887

Crafts, L. W., \& Rotter, J. B. (1955). Social learning and clinical psychology. The American Journal of Psychology, 68(4). https://doi.org/1.2307/1418818

Demerouti, E., \& Bakker, A. B. (2011). The Job Demands-Resources model: Challenges for future research. SA Journal of Industrial Psychology, 37(2), 1-9. https://doi.org/1.4102/sajip.v37i2.974

Dijksterhuis, A., \& Aarts, H. (2010). Goals, attention, and (Un)consciousness. Annual Review of Psychology, 61, 467-490. https://doi.org/10.1146/annurev.psych.093008.100445

Doran, G. T. (1981). There's a S.M.A.R.T way to write management's goals and objectives. Management Review, 70(11), 35-36. 
Ehrlich, C. (2012). Be careful what you wish for but also why you wish for it - Goal-striving reasons and subjective well-being. Journal of Positive Psychology, 7(6), 493-503. https://doi.org/1.1080/1743976.2012.721382

Elliot, A. J. (1999). Approach and avoidance motivation and achievement goals. Educational Psychologist, 34(3), 169-189. https://doi.org/1.1207/s15326985ep3403_3

Elliot, A. J., \& Thrash, T. M. (2001). Achievement goals and the hierarchical model of achievement motivation. Educational Psychology Review, 13(2), 139-156.

Elliot, A. J., McGregor, H. A., \& Gable, S. (1999). Achievement goals, study strategies, and exam performance: A mediational analysis. Journal of Educational Psychology, 91(3), 549-563. https://doi.org/1.1037/0022-0663.91.3.549

Freund, A. M., Hennecke, M., \& Mustafić, M. (2012). On gains and losses, means and ends: Goal orientation and goal focus across adulthood. In R. M. Ryan (Ed.), The Oxford handbook of human motivation (pp. 280-300). Oxford University Press.

Galvin, B. M., Randel, A. E., Collins, B. J., \& Johnson, R. E. (2018). Changing the focus of locus (of control): A targeted review of the locus of control literature and agenda for future research. Journal of Organizational Behavior, 39(7), 820-833.

Golino, H. F., \& Epskamp, S. (2017). Exploratory graph analysis: A new approach for estimating the number of dimensions in psychological research. PLOS One, 12(6), e0174035. https://doi.org/1.1371/journal.pone.0174035

Golino, H., Christensen, A., Moulder, R., \& Garrido, L. E. (2021). EGAnet: Exploratory Graph Analysis - A Framework for Estimating the Number of Dimensions in Multivariate Data Using Network Psychometrics (.9.8) [Computer software]. https://CRAN.Rproject.org/package=EGAnet 
Gollwitzer, P. M. (1999). Implementation intentions: Strong effects of simple plans. American Psychologist, 54(7), 493-503. https://doi.org/10.1037/0003-066X.54.7.493

Gollwitzer, P. M., \& Oettingen, G. (2012). Goal pursuit. In R. M. Ryan (Ed.), The Oxford Handbook of Human Motivation (pp. 208-231). Oxford University Press.

Gollwitzer, P. M., Sheeran, P., Michalski, V., \& Seifert, A. E. (2009). When Intentions Go Public: Does Social Reality Widen the Intention-Behavior Gap? Psychological Science, 20(5), 612-618. https://doi.org/10.1111/j.1467-9280.2009.02336.x

Harkin, B., Webb, T. L., Chang, B. P. I., Prestwich, A., Conner, M., Kellar, I., Benn, Y., \& Sheeran, P. (2016). Does monitoring goal progress promote goal attainment? A metaanalysis of the experimental evidence. Psychological Bulletin, 142(2), 198-229. https://doi.org/1.1037/bul0000025

Hirschfeld, G., \& Brachel, R. von. (2019). Improving Multiple-Group confirmatory factor analysis in $\mathrm{R}$ - A tutorial in measurement invariance with continuous and ordinal indicators. Practical Assessment, Research, and Evaluation, 19(1). https://doi.org/10.7275/qazy-2946

Hirsh, J. B., Lu, J. G., \& Galinsky, A. D. (2018). Moral Utility Theory: Understanding the motivation to behave (un)ethically. Research in Organizational Behavior, 38, 43-59. https://doi.org/10.1016/j.riob.2018.10.002

Hollenbeck, J. R., Klein, H. J., O’Leary, A. M., \& Wright, P. M. (1989). Investigation of the construct validity of a self-report measure of goal commitment. Journal of Applied Psychology, 74(6), 951-956. https://doi.org/10.1037/0021-9010.74.6.951

Hope, N. H., Milyavskaya, M., Holding, A. C., \& Koestner, R. (2016). The humble path to progress: Goal-specific aspirational content predicts goal progress and goal vitality. 
Personality and Individual Differences, 90, 99-107. https://doi.org/10.1016/j.paid.2015.10.038

Hulleman, C. S., Schrager, S. M., Bodmann, S. M., \& Harackiewicz, J. M. (2010). A metaanalytic review of achievement goal measures: Different labels for the same constructs or different constructs with similar labels? Psychological Bulletin, 136(3), 422-449. http://dx.doi.org/10.1037/a0018947

Jiang, Y., \& Kleitman, S. (2015). Metacognition and motivation: Links between confidence, selfprotection and self-enhancement. Learning and Individual Differences, 37, 222-23. https://doi.org/10.1016/j.lindif.2014.11.025

Jung, C. S., \& Rainey, H. G. (2011). Organizational goal characteristics and public duty motivation in U.S. federal agencies. Review of Public Personnel Administration, 31(1), 28-47. https://doi.org/10.1177/0734371X10394404

Klein, H. J., Lount, R. B., Jr., Park, H. M., \& Linford, B. J. (2020). When goals are known: The effects of audience relative status on goal commitment and performance. Journal of Applied Psychology, 105(4), 372-389. http://dx.doi.org/10.1037/apl0000441

Kleingeld, A., van Mierlo, H., \& Arends, L. (2011). The effect of goal setting on group performance: A meta-analysis. Journal of Applied Psychology, 96(6), 1289-1304. https://doi.org/10.1037/a0024315

Koestner, R., Lekes, N., Powers, T. A., \& Chicoine, E. (2002). Attaining personal goals: Selfconcordance plus implementation intentions equals success. Journal of Personality and Social Psychology, 83(1), 231-244. https://doi.org/10.1037/0022-3514.83.1.231

Kung, F. Y. H., \& Scholer, A. A. (2018). A network model of goals boosts convergent creativity performance. Frontiers in Psychology, 9, 1-12. https://doi.org/10.3389/fpsyg.2018.01910 
Kung, F. Y. H., \& Scholer, A. A. (2020). The pursuit of multiple goals. Social and Personality Psychology Compass, 14(1), 1-14. https://doi.org/10.1111/spc3.12509

Lappi, S. K., \& Wilkowski, B. M. (2020). The generalized approach, attainMent, maintenance, and avoidance (GAMMA) motivation scale: development, validation, and theoretical contribution. Motivation and Emotion, 44(3), 389-409. https://doi.org/10.1007/s11031019-09817-2

Latham, G. P., \& Locke, E. A. (1991). Self-regulation through goal setting. Organizational Behavior and Human Decision Processes, 50(2), 212-247. https://doi.org/10.1016/07495978(91)90021-K

Li, C. H. (2016). Confirmatory factor analysis with ordinal data: Comparing robust maximum likelihood and diagonally weighted least squares. Behavior Research Methods, 48(3), 936-949. https://doi.org/10.3758/s13428-015-0619-7

Little, B. R. (1983). Personal projects: A rationale and method for investigation. Environment and Behavior, 15(3), 273-309. https://doi.org/10.1177/0013916583153002

Locke, E. A., \& Latham, G. P. (2002). Building a practically useful theory of goal setting and task motivation: A 35-year odyssey. American Psychologist, 57(9), 705-717. https://doi.org/10.1037/0003-066X.57.9.705

Locke, E. A., Chah, D. O., Harrison, S., \& Lustgarten, N. (1989). Separating the effects of goal specificity from goal level. Organizational Behavior and Human Decision Processes, 43(2), 270-287. https://doi.org/10.1016/0749-5978(89)90053-8

Louro, M. J., Pieters, R., \& Zeelenberg, M. (2007). Dynamics of multiple-goal pursuit. Journal of Personality and Social Psychology, 93(2), 174-193. https://doi.org/10.1037/00223514.93.2.174 
Lunenburg, F. (2011). Goal-Setting Theory of Motivation. International Journal of Management, Business, and Administration, 15(1), 1-6.

Lynch, J. G., Netemeyer, R. G., Spiller, S. A., \& Zammit, A. (2010). A generalizable scale of propensity to plan: The long and the short of planning for time and for money. Journal of Consumer Research, 37(1), 108-128. https://doi.org/10.1086/649907

Malecki, C. K., \& Demaray, M. K. (2003). What type of support do they need? Investigating student adjustment as related to emotional, informational, appraisal, and instrumental Support. School Psychology Quarterly, 18(3), 231-252. http://dx.doi.org/10.1521/scpq.18.3.231.22576

McGregor, I., \& Little, B. R. (1998). Personal projects, happiness, and meaning: On doing well and being yourself. Journal of Personality and Social Psychology, 74(2), 494-512. https://doi.org/10.1037/0022-3514.74.2.494

McGregor, I., Prentice, M., \& Nash, K. (2013). Anxious Uncertainty and Reactive Approach Motivation (RAM) for religious, idealistic, and lifestyle extremes. Journal of Social Issues, 69(3), 537-563. https://doi.org/10.1111/josi.12028

Mento, A. J., Steel, R. P., \& Karren, R. J. (1987). A meta-analytic study of the effects of goal setting on task performance: 1966-1984. Organizational Behavior and Human Decision Processes, 39(1), 52-83. https://doi.org/10.1016/0749-5978(87)90045-8

Millsap, R. E., \& Yun-Tein, J. (2004). Assessing factorial invariance in ordered-categorical measures. Multivariate Behavioral Research, 39(3), 479-515. https://doi.org/10.1207/S15327906MBR3903_4 
Milyavskaya, M., \& Werner, K. M. (2018). Goal pursuit: Current state of affairs and directions for future research. Canadian Psychology/Psychologie canadienne, 59(2), 163175. https://doi.org/10.1037/cap0000147

Murayama, K., \& Elliot, A. J. (2019). Achievement Goals. In R. M. Ryan (Ed.), The Oxford Handbook of Human Motivation (pp. 227-245). Oxford University Press. https://doi.org/10.1093/oxfordhb/9780190666453.013.13

Murayama, K., \& Elliot, A. J. (2019). Achievement Goals. In R. M. Ryan (Ed.), The Oxford Handbook of Human Motivation (pp. 227-245). Oxford University Press. https://doi.org/10.1093/oxfordhb/9780190666453.013.13

Neal, A., Ballard, T., \& Vancouver, J. B. (2017). Dynamic self-regulation and multiple-goal pursuit. Annual Review of Organizational Psychology and Organizational Behavior, 4(1), 401-423. https://doi.org/10.1146/annurev-orgpsych-032516-113156

Pintrich, P. R. (2000). An achievement goal theory perspective on issues in motivation terminology, theory, and research. Contemporary Educational Psychology, 25(1), 92104. doi:10.1006/ceps.1999.1017

Pomaki, G., Karoly, P., \& Maes, S. (2009). Linking goal progress to subjective well-being at work: The moderating role of goal-related self-efficacy and attainability. Journal of Occupational Health Psychology, 14(2), 206-218. https://doi.org/10.1037/a0014605

R Core Team. (2016). R: A Language and Environment for Statistical Computing. Vienna, Austria. Retrieved from https://www.R-project.org/

Ren, J., Ding, D., Wu, Q., Liu, C., Hao, Y., Cui, Y., Sun, H., Ning, N., Li, Y., Kang, Z., Shan, L., Zhao, M., \& Liu, B. (2019). Financial affordability, health insurance, and use of health care services by the elderly: Findings from the china health and retirement 
longitudinal study. Asia Pacific Journal of Public Health, 31(6), 510-521. https://doi.org/10.1177/1010539519877054

Rosseel, Y. (2012). lavaan: An R Package for Structural Equation Modeling. Journal of Statistical Software, 48(2), 1-36. https://doi.org/10.18637/jss.v048.i02

Russell, D. (1982). The Causal Dimension Scale: A measure of how individuals perceive causes. Journal of Personality and Social Psychology, 42(6), 11371145. https://doi.org/10.1037/0022-3514.42.6.1137

Senko, C., \& Dawson, B. (2017). Performance-approach goal effects depend on how they are defined: Meta-analytic evidence from multiple educational outcomes. Journal of Educational Psychology. https://doi.org/10.1037/edu0000160

Sheldon, K. M., Corcoran, M., \& Prentice, M. (2019). Pursuing eudaimonic functioning versus pursuing hedonic well-being: The first goal succeeds in its aim, whereas the second does not. Journal of Happiness Studies, 20(3), 919-933. https://doi.org/10.1007/s10902-0189980-4

Sheldon, K. M., Osin, E. N., Gordeeva, T. O., Suchkov, D. D., \& Sychev, O. A. (2017). Evaluating the Dimensionality of Self-Determination Theory's Relative Autonomy Continuum. Personality and Social Psychology Bulletin, 43(9), 1215-1238. https://doi.org/10.1177/0146167217711915

Sheldon, K. M., Prentice, M., \& Osin, E. (2019). Rightly crossing the Rubicon: Evaluating goal self-concordance prior to selection helps people choose more intrinsic goals. Journal of Research in Personality, 79, 119-129. https://doi.org/1.1016/j.jrp.2019.03.001

Stamatogiannakis, A., Chattopadhyay, A., \& Chakravarti, D. (2018). Attainment versus maintenance goals: Perceived difficulty and impact on goal choice. Organizational 
Behavior and Human Decision Processes, 149, 17-34.

https://doi.org/1.1016/i.obhdp.2018.09.002

Strathman, A., Gleicher, F., Boninger, D. S., \& Edwards, C. S. (1994). The consideration of future consequences: Weighing immediate and distant outcomes of behavior. Journal of Personality and Social Psychology, 66(4), 742-752. https://doi.org/10.1037/00223514.66.4.742

Su, R., Tay, L., \& Diener, E. (2014). The development and validation of the Comprehensive Inventory of Thriving (CIT) and the Brief Inventory of Thriving (BIT). Applied Psychology: Health and Well-Being, 6(3), 251-279. https://doi.org/10.1111/aphw.12027

Vancouver, J. B., \& Austin, J. T. (1996). Goal constructs in psychology: Structure, process, and content. Psychological Bulletin, 120(3), 338-375.

Wefald, A. J., \& Downey, R. G. (2009). Construct dimensionality of engagement and its relation with satisfaction. The Journal of Psychology, 143(1), 91-112. https://doi.org/10.3200/JRLP.143.1.91-112

Werner, K. M., Milyavskaya, M., Foxen-Craft, E., \& Koestner, R. (2016). Some goals just feel easier: Self-concordance leads to goal progress through subjective ease, not effort. Personality and Individual Differences, 96, 237-242. https://doi.org/10.1016/j.paid.2016.03.002

Wood, R. E., Mento, A. J., \& Locke, E. A. (1987). Task complexity as a moderator of goal effects: A meta-analysis. Journal of Applied Psychology, 72(3), 416-425. https://doi.org/10.1037/0021-9010.72.3.416

Wrosch, C., Scheier, M. F., Miller, G. E., Schulz, R., \& Carver, C. S. (2003). Adaptive SelfRegulation of Unattainable Goals: Goal Disengagement, Goal Reengagement, and 
Subjective Well-Being. Personality and Social Psychology Bulletin, 29(12), 1494-1508. https://doi.org/10.1177/0146167203256921

Yik, M., Russell, J. A., \& Steiger, J. H. (2011). A 12-point circumplex structure of core affect. Emotion, 11(4), 705-731. https://doi.org/10.1037/a0023980 